\title{
Regioselective Mono and Homo/hetero Dihalogenation of the Benzothioxanthene Monoimide
}

Clement Dalinot, Pablo Simon Marques, Jose Maria Andrés Castán, Pierre Josse, Magali Allain, Laura Abad Galan, Cyrille Monnereau, Olivier MAURY, Philippe Blanchard, Clement Cabanetos

Submitted date: $18 / 02 / 2020$ - Posted date: 20/02/2020

Licence: CC BY-NC-ND 4.0

Citation information: Dalinot, Clement; Simon Marques, Pablo; Andrés Castán, Jose Maria; Josse, Pierre; Allain, Magali; Abad Galan, Laura; et al. (2020): Regioselective Mono and Homo/hetero Dihalogenation of the Benzothioxanthene Monoimide. ChemRxiv. Preprint. https://doi.org/10.26434/chemrxiv.11865765.v1

Through the preparation and characterization of five new derivatives, the regioselective mono and di, homo and hetero, halogenation of the benzothioxanthene (BTXI) core is demonstrated herein. All structurally solved by X-ray crystallography, these complementary functionalized building blocks open doors to the design of new symmetrical and asymmetrical $\pi$-conjugated systems based on this promising but still under-explored rylene.

File list (2)

Regioselective mono and homohetero dihalogenation of th... (1.00 MiB) view on ChemRxiv • download file Regioselective mono and homohetero dihalogenation of th... (2.21 MiB) view on ChemRxiv • download file 


\title{
Regioselective mono and homo/hetero dihalogenation of the benzothioxanthene monoimide
}

\author{
Clément Dalinot, ${ }^{[a]}$ Pablo Simón Marqués, ${ }^{[a]}$ José M. Andrés Castán, ${ }^{[a]}$ Pierre Josse, ${ }^{[a]}$ Magali \\ Allain, ${ }^{[a]}$ Laura Abad Galán, ${ }^{[b]}$ Cyrille Monnereau, ${ }^{[b]}$ Olivier Maury, ${ }^{[b]}$ Philippe Blanchard, ${ }^{[a]}$ \\ Clément Cabanetos*[a] \\ [a] MOLTECH-Anjou, CNRS UMR 6200, University of Angers, 2 Bd Lavoisier, 49045, France \\ E-mail: clement.cabanetos@univ-angers.fr \\ [b] Univ Lyon, ENS de Lyon, CNRS UMR 5182, Université Claude Bernard Lyon 1, F-69342 Lyon, France
}

\begin{abstract}
Through the preparation and characterization of five new derivatives, the regioselective mono and di, homo and hetero, halogenation of the benzothioxanthene (BTXI) core is demonstrated herein. All structurally solved by X-ray crystallography, these complementary functionalized building blocks open doors to the design of new symmetrical and asymmetrical $\pi$-conjugated systems based on this promising but still under-explored rylene.
\end{abstract}

\section{Introduction}

Over the past decades, the naphthalene (NDI) and perylene (PDI) diimides have emerged as reference building blocks in the field of organic electronics due to their excellent thermal and photochemical stability, synthetic tunability as well as specific electrochemical and high charge transport properties (Figure 1). ${ }^{1-6}$ Although belonging to the imide-containing rylene family, the benzothioxanthene monoimide (BTXI) has not triggered such research interest, until recently. ${ }^{7}$<smiles>[R]N1C(=O)c2ccc3c4c(ccc(c24)C1=O)C(=O)N([R])C3=O</smiles>

NDI<smiles>[R]N1C(=O)c2ccc3c4ccc5c6c(ccc(c7ccc(c2c37)C1=O)c64)C(=O)N([R])C5=O</smiles>

PDI

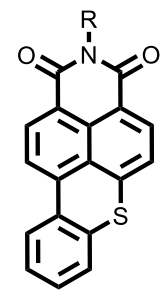

BTXI

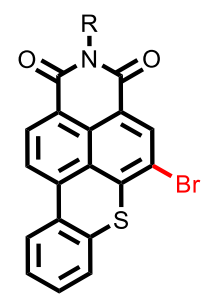

BTXI-Br

Figure 1. Structures of naphthalene diimide (NDI), perylene diimide (PDI), benzothioxanthene monoimide (BTXI) and the brominated derivative BTXI-Br.

Synthesized in the 70's and solely functionalized on the $N$-position for post-grafting and/or solubility purposes, ${ }^{8-12}$ we indeed recently demonstrated the selective mono-bromination (Figure 1, BTXI-Br) and use of this new promising block to prepare new $\pi$-conjugated systems via conventional palladium catalyzed cross-coupling reactions for organic photovoltaic applications. ${ }^{13-15}$ As a step towards new design principles, and therefore potential applications, we report herein a systematic halogenation study of the BTXI block to afford complementary mono- and di-halogenated derivatives.

\section{Results and Discussion}

Hence, and from our early reported procedure, ${ }^{13}$ where the BTXI was efficiently mono-brominated in the presence of 1.1 equivalents of bromine (Table 1, entry 1), we started to investigate the reactivity of additional and safer sources of bromine atoms. 
To that end, the reactivity of the cheap and well-known $N$-bromosuccinimide (NBS) was first evaluated. It turned out that regardless of the reaction time (from few minutes to hours), temperature (room temperature or reflux) and nature of the solvent (chloroform or $N, N$-dimethylformamide), the entirety of the starting material was systematically recovered (Table 1, entries 2-5). However, while activating the NBS with $p$ toluenesulfonic acid in ethanol barely improved the conversion (Table 1, entry 6), ${ }^{16}$ it was found that mechanochemistry can be an interesting tool to prepare the target BTXI-Br in high yield (Table 1, entry 7). ${ }^{17}$ However, this solvent-free method requires a large excess of reactant (12 equivalents) to reach a full conversion of the starting material (Table 1, entry 9).

Table 1. Experimental conditions evaluated in this study to mono-brominate the BTXI. R.T. = room temperature.

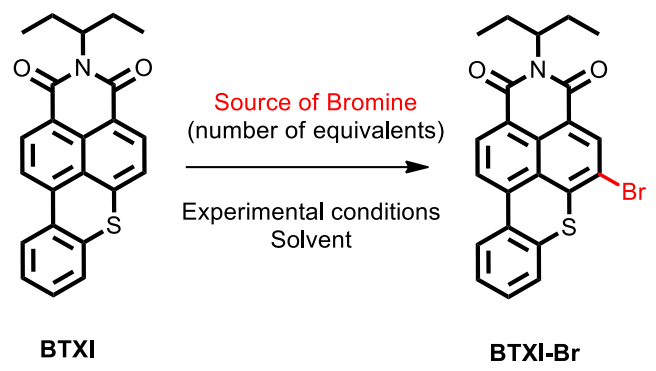

\begin{tabular}{|c|c|c|c|c|c|}
\hline Entry & Source of Bromine atom & $\begin{array}{l}\text { Number of } \\
\text { equivalents }\end{array}$ & Solvent & $\begin{array}{l}\text { Experimental } \\
\text { conditions }\end{array}$ & $\begin{array}{c}\text { Synthetic Yield } \\
\text { of isolated } \\
\text { BTXI-Br }\end{array}$ \\
\hline 1 & Bromine $\left(\mathrm{Br}_{2}\right)$ & 1.1 & dichloromethane & R.T.; overnight & $93 \%$ \\
\hline 2 & $N$-bromosuccinimide & 4.0 & $N, N$-dimethylformamide & R.T.; overnight & $0 \%$ \\
\hline 3 & $N$-bromosuccinimide & 4.0 & chloroform & R.T.; overnight & $0 \%$ \\
\hline 4 & $\mathrm{~N}$-bromosuccinimide & 4.0 & $N, N$-dimethylformamide & reflux; overnight & $0 \%$ \\
\hline 5 & $N$-bromosuccinimide & 4.0 & chloroform & reflux; overnight & $0 \%$ \\
\hline 6 & $N$-bromosuccinimide & 4.0 & ethanol & $\begin{array}{l}p \text {-toluenesulfonic acid; } \\
\text { microwave; } 100^{\circ} \mathrm{C} \\
15 \text { minutes }\end{array}$ & $11 \%$ \\
\hline 7 & $N$-bromosuccinimide & 3 & no solvent & $\begin{array}{l}\text { ball-milling; } \\
1 \text { hour }\end{array}$ & $33 \%$ \\
\hline 8 & $N$-bromosuccinimide & 6 & no solvent & $\begin{array}{l}\text { ball-milling; } \\
1 \text { hour }\end{array}$ & $60 \%$ \\
\hline 9 & $N$-bromosuccinimide & 12 & no solvent & $\begin{array}{l}\text { ball-milling; } \\
1 \text { hour }\end{array}$ & $99 \%$ \\
\hline 10 & Dibromoisocyanuric acid & 1.1 & $\mathrm{~N}, \mathrm{~N}$-dimethylformamide & R.T.; overnight & $95 \%$ \\
\hline 11 & Pyridinium tribromide & 1.1 & dichloromethane & R.T.; overnight & $47 \%$ \\
\hline 12 & Pyridinium tribromide & 1.1 & dichloromethane & $\begin{array}{c}\text { microwaves, } 100^{\circ} \mathrm{C} ; 1 \\
\text { hour }\end{array}$ & $52 \%$ \\
\hline 13 & Pyridinium tribromide & 2.2 & dichloromethane & $\begin{array}{c}\text { microwaves, } 100^{\circ} \mathrm{C} ; 1 \\
\text { hour }\end{array}$ & $94 \%$ \\
\hline
\end{tabular}

In contrast, this was not the case for the dibromoisocyanuric acid since only 1.1 molar equivalents of this strong bromine source were indeed necessary to efficiently convert the BTXI into the target compound. Moreover, it is important to note that the reaction occurs under very mild conditions, i.e., at room temperature and overnight (Table 1, entry 10). However, considering the relative high price of this reagent, the use of a cheaper one but still known to be a strong and solid source of bromine was finally assessed, namely the pyridinium tribromide. When engaged under the previously described mild conditions, i.e., 1.1 equivalents at room temperature and overnight (Table 1, entry 11), a maximum conversion of 50\% was reached (47\% isolated), corresponding to a mixture of the target BTXI-Br and the starting material (BTXI). In an attempt to improve the reactivity, the conventional oil bath was directly replaced by microwave irradiations (Table 1, entry 12). Unfortunately, a well-balanced blend of BTXI-Br and BTXI was once 
again recovered even after one hour of stirring at $100{ }^{\circ} \mathrm{C}$. According to these observations, it was decided to double the amount of brominating agent (Table 1, entry 13) resulting in a full conversion, thus suggesting that the quantity of the pyridinium tribromide was the limiting parameter.

On the other hand, characterization of the crude by mass spectrometry also revealed the presence of a minor product attributed to a dibrominated species. As an important building block for a multi functionalization of the BTXI core, the second insertion of a bromine atom was naturally investigated. To do so, the amount of pyridinium tribromide was significantly increased to 5, 10 and even 20 equivalents under the same heating conditions (Table 2, entries 1-3). It turned out that using a large excess of this brominating agent indeed generated a dibrominated species but with a maximum yield of $12 \%$, the major product still being in these conditions the mono derivative, ie, the BTXI-Br.

Hence, owing to its high reactivity, 2.2 equivalents of dibromoisocyanuric acid were subsequently added to a solution of BTXI (Table 2, entry 4). After 16 hours under reflux and the total consumption of the starting material, only one spot migrated on the thin layer chromatography (TLC), corresponding, after purification, to a dibrominated compound. With a resulting yield of $\mathrm{ca} .32 \%$, the quantity of brominated agent was increased to 5.0 equivalents (Table 2 , entry 5). In these conditions, although only a single dibrominated derivative was recovered from the purification, the synthetic yield dropped to $18 \%$, resulting from the higher amount of polar by-products stuck at the start of the chromatography column.

Consequently, the BTXI was finally exposed to an increasing quantity of bromine and the solutions were refluxed overnight (Table 2, entries 6-8). While, in all cases, the starting material was systematically consumed, the full conversion into a dibrominated derivative was only reached with 20 equivalents (Table 2 , entry 8).

All isolated Br-BTXI-Br products were analyzed by ${ }^{1} \mathrm{H}$ NMR revealing a perfect superimposition of their spectra, thus confirming, in consistency with the TLC ( same $\mathrm{R}_{\mathrm{f}}=0.6$ in toluene), the generation of the same and unique dibrominated compound regardless of the nature of the brominating agent. Luckily, single crystals were successfully grown revealing the exact grafting of the second bromine atom at the 11 position as depicted in Figure 2.

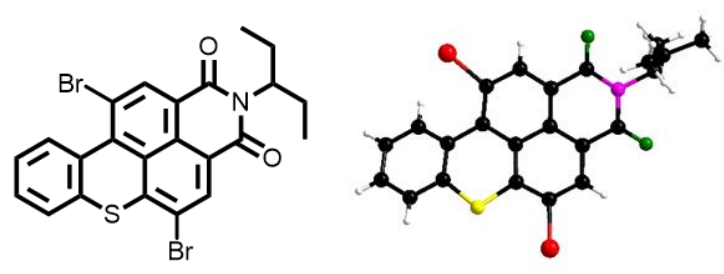

Figure 2. Molecular structure of the Br-BTXI-Br obtained by X-ray diffraction.

In parallel, the iodination of the BTXI was also investigated to extend the range of functionalization and reactivity (Table 3 ). 
Table 2. Experimental conditions evaluated for the preparation of a dibrominated BTXI.

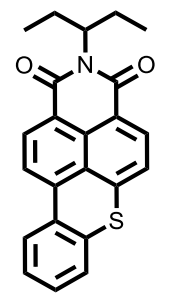

BTXI

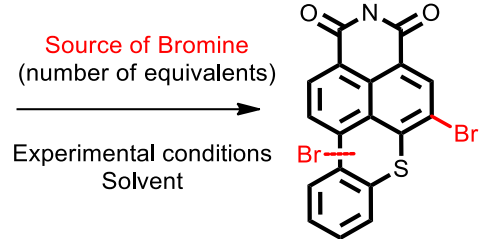

$\mathrm{Br}-\mathrm{BTXI-Br}$

\begin{tabular}{|c|c|c|c|c|c|}
\hline Entry & Source of Bromine atom & $\begin{array}{l}\text { Number of } \\
\text { equivalents }\end{array}$ & Solvent & Experimental conditions & $\begin{array}{c}\text { Synthetic yield of } \\
\text { BTXI/BTXI-Br and } \\
\text { Br-BTXI-Br }\end{array}$ \\
\hline 1 & Pyridinium tribromide & 5.0 & dichloromethane & microwaves, $100^{\circ} \mathrm{C} ; 1$ hour & $0 \% / 93 \% / 5 \%$ \\
\hline 2 & Pyridinium tribromide & 10.0 & dichloromethane & microwaves, $100^{\circ} \mathrm{C} ; 1$ hour & $0 \% / 85 \% / 11 \%$ \\
\hline 3 & Pyridinium tribromide & 20.0 & dichloromethane & microwaves, $100^{\circ} \mathrm{C}$; 1 hour & $0 \% / 83 \% / 12 \%$ \\
\hline 4 & Dibromoisocyanuric acid & 2.2 & $\mathrm{~N}, \mathrm{~N}$-dimethylformamide & reflux.; overnight & $0 \% / 0 \% / 32 \%$ \\
\hline 5 & Dibromoisocyanuric acid & 5.0 & $\mathrm{~N}, \mathrm{~N}$-dimethylformamide & reflux.; overnight & $0 \% / 0 \% / 18 \%$ \\
\hline 6 & Bromine & 5.0 & dichloromethane & reflux; overnight & 0\%/78\%/19\% \\
\hline 7 & Bromine & 10.0 & dichloromethane & reflux; overnight & $0 \% / 23 \% / 73 \%$ \\
\hline 8 & Bromine & 20.0 & dichloromethane & reflux; overnight & 0\%/0\%/98\% \\
\hline
\end{tabular}

Mild and green conditions, reported by Gohier and coworkers, ${ }^{16}$ using $N$-iodosuccinimide in ethanol with a catalytic amount of $p$-toluenesulfonic acid, were first investigated (Table 3, entry 1). Stirring the reaction mixture overnight at $60{ }^{\circ} \mathrm{C}$ successfully led to the formation of a new compound. Once isolated in good yield by column chromatography, the latter was subsequently analyzed by mass spectrometry and NMR experiments revealing the presence of a single iodine atom grafted on the constituting naphthyl moiety of BTXI, the exact position of which was, once again, solved by single crystal X-ray diffraction (Figure 3).
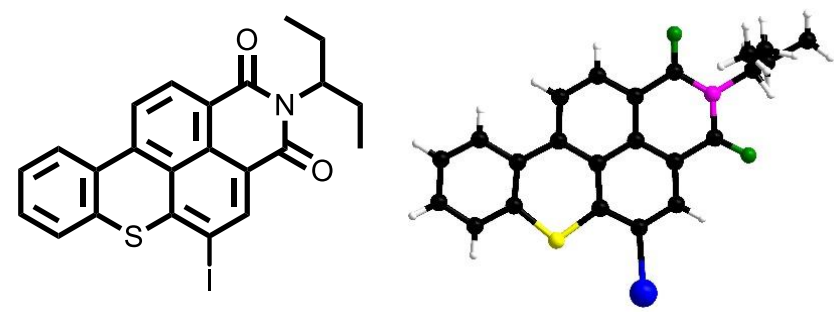

Figure 3. Molecular structure of the BTXI-I obtained by X-ray diffraction. 
Table 3. Experimental conditions for the synthesis of the mono- and di-iodinated BTXI based derivatives (BTXI-I and I-BTXI-I). R.T. = room temperature.

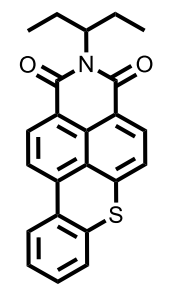

BTXI

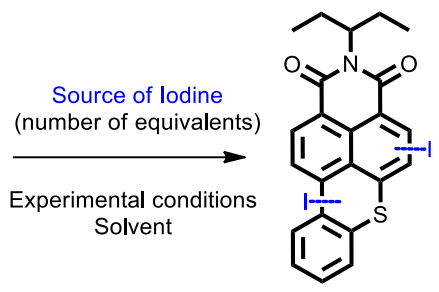

I-BTXI-I

\begin{tabular}{|c|c|c|c|c|c|}
\hline Entry & Source of lodine atom & $\begin{array}{l}\text { Number of } \\
\text { equivalents }\end{array}$ & Solvent & Experimental conditions & $\begin{array}{l}\text { Synthetic yield } \\
\text { of BTXI/BTXI-I } \\
\text { and I-BTXI-I }\end{array}$ \\
\hline 1 & $\mathrm{~N}$-iodosuccinimide & 2.0 & ethanol & $\begin{array}{l}p \text {-toluenesulfonic acid; } \\
60^{\circ} \mathrm{C} \text {; ; overnight }\end{array}$ & $30 \% / 67 \% / 0 \%$ \\
\hline 2 & $\mathrm{~N}$-iodosuccinimide & 2.0 & ethanol & $\begin{array}{c}p \text {-toluenesulfonic acid; } \\
\text { microwave, } 100^{\circ} \mathrm{C} ; 1 \\
\text { hour }\end{array}$ & $12 \% / 80 \% / 0 \%$ \\
\hline 3 & $\mathrm{~N}$-iodosuccinimide & 4.0 & ethanol & $\begin{array}{l}p \text {-toluenesulfonic acid; } \\
\text { microwave, } 100^{\circ} \mathrm{C} ; 1 \\
\text { hour }\end{array}$ & $0 \% / 100 \% / 0 \%$ \\
\hline 4 & lodine/lodic acid & $2.5 /$ cat. & $\begin{array}{c}\text { acetic acid:sulfuric } \\
\text { acid:water: } \mathrm{CHCl}_{3} \\
(1: 0.02: 0.2: 0.08 \\
\text { /v:v:v:v) }\end{array}$ & R.T.; overnight & $0 \% / 67 \% / 3 \%$ \\
\hline 5 & lodine/lodic acid & $2.5 /$ cat. & $\begin{array}{c}\text { acetic acid:sulfuric } \\
\text { acid:water: } \mathrm{CHCl}_{3} \\
(1: 0.02: 0.2: 0.08 \\
\text { /v:v:v:v) }\end{array}$ & $90^{\circ} \mathrm{C}$; overnight & $0 \% / 38 \% / 19 \%$ \\
\hline
\end{tabular}

As for BTXI-Br, the iodination occurs on the rylene core at the $\beta$-position with regards to the sulfur atom. In addition to changing the heating method (Table 3, entry 2), the full conversion of the BTXI in this new derivative, namely BTXI-I, was only achieved by increasing the quantity of $N$-iodosuccinimide (Table 3 , entry 3). Interestingly, though a large excess of this reagent was used, no multi-halogenated compound was detected in the crude. In an attempt to generate such species, a stronger method based on the use of the iodic acid/iodine couple in a mixture of acetic and sulfuric acid, water and chloroform was considered and evaluated. After 16 hours of stirring at room temperature, TLCs highlighted the formation of two compounds (Table 3, entry 4). Once purified by simple column chromatography, the major product was found to be the above mentioned mono-iodinated BTXI (BTXI-I) while the second, isolated with a low yield, corresponds to a di-iodinated derivative. In stark contrast with Br-BTXI-Br where both bromine atoms are localized on the naphthyl ring, ${ }^{1} \mathrm{H}$ NMR experiments of the new I-BTXI-I suggested a functionalization of the constituting phenyl ring (Figure 4, purple tagged protons). 
Figure 4. Comparison of BTXI, BTXI-I and I-BTXI-I ${ }^{1} \mathrm{H}$ NMR spectra recorded at room temperature in deuterated chloroform.

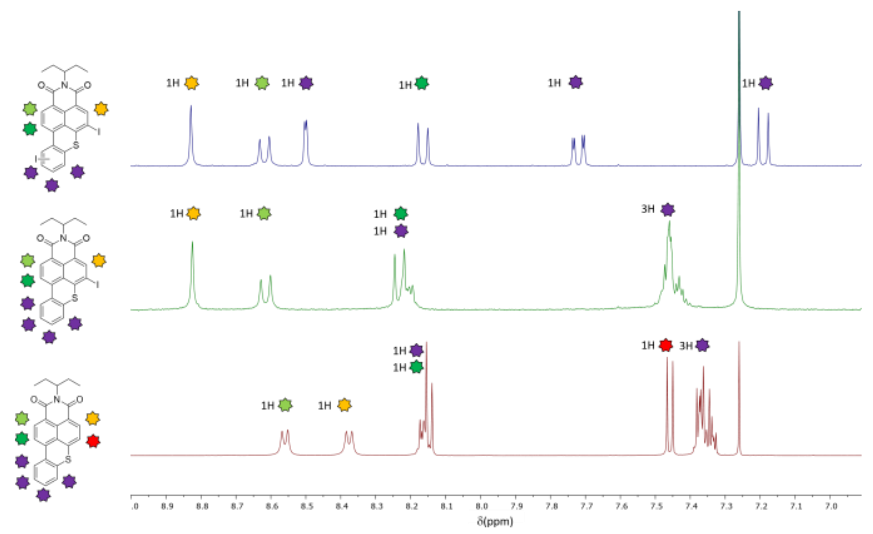

While the integrity of the naphthyl constituting protons were recovered when comparing the spectra of both BTXI-I and I-BTXI-I, the multiplet centered at ca. $7.45 \mathrm{ppm}$, that comprises three hydrogen atoms, splits into a doublet (at $7.19 \mathrm{ppm}$ ) and a doublet of doublets (at $7.72 \mathrm{ppm}$ ) of one proton each. Moreover, the characteristic doublet centered at $8.5 \mathrm{ppm}$ of I-BTXI-I, also attributed to a phenyl proton, appears significantly deshielded (compared to its BTXI-I analogue) thus supporting a close-by halogenation. Single crystal X-ray diffraction later confirmed these suppositions, thus revealing the exact position of the second iodine atom, corresponding to a functionalization in para of the sulfur atom (Figure 5).

Figure 5. Molecular structure of the I-BTXI-I obtained by X-ray diffraction

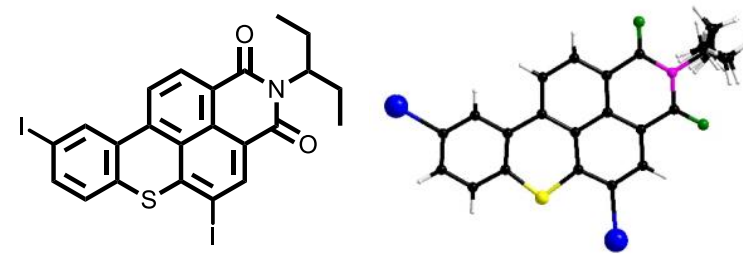

In a further attempt to improve the conversion into this new bis-functionalized derivative, the temperature of the reaction was increased to $90{ }^{\circ} \mathrm{C}$ for $24 \mathrm{~h}$ (Table 3, entry 5). While a larger amount of I-BTX-I was indeed isolated, these conditions also led to more unidentified and mostly insoluble by-products. Hence, to take it to the next level, these reactions were finally complementarily combined to afford hetero- and regiospecific dihalogenated derivatives (Scheme 1).

To do so, BTXI-Br was successfully iodinated in acidic conditions in the presence of iodic acid and iodine. As for I-B TXI-I, the iodine atom was found to be localized on the phenyl ring in para position with respect to the sulfur atom as evidenced by ${ }^{1} \mathrm{H}$ NMR and single crystal X-ray diffraction (I-BTXI-Br, Figure 6). In parallel, BTXI-I was first exposed to 20 equivalents of bromine. After reflux overnight, TLCs revealed the total consumption of the starting compound and generation of a single compound. However, once isolated and characterized, the latter turned out to be the dibrominated Br-BTXI-Br. Consequently, to avoid the halogen exchange reaction, the excess of bromine was replaced by only 1.1 equivalents of dibromoisocyanuric acid. First highlighted by TLCs, a new compound, whose $\mathrm{R}_{\mathrm{f}}$ was found to be different from that of the Br-BTXI-Br, was successfully isolated in good yield after the total consumption of the starting material and purification of the crude. Mass spectrometry confirmed the presence of both a bromine and an iodine atom on this new BTXI derivative and ${ }^{1} \mathrm{H}$ NMR suggested a functionalization on the naphthyl 
ring as for Br-BTXI-Br (see SI). Luckily, crystals of good quality were successfully grown and analyzed by X-ray diffraction confirming both hypothesized structures (Figure 6).

Scheme 1. Regioselective hetero dihalogenated derivatives reported herein.

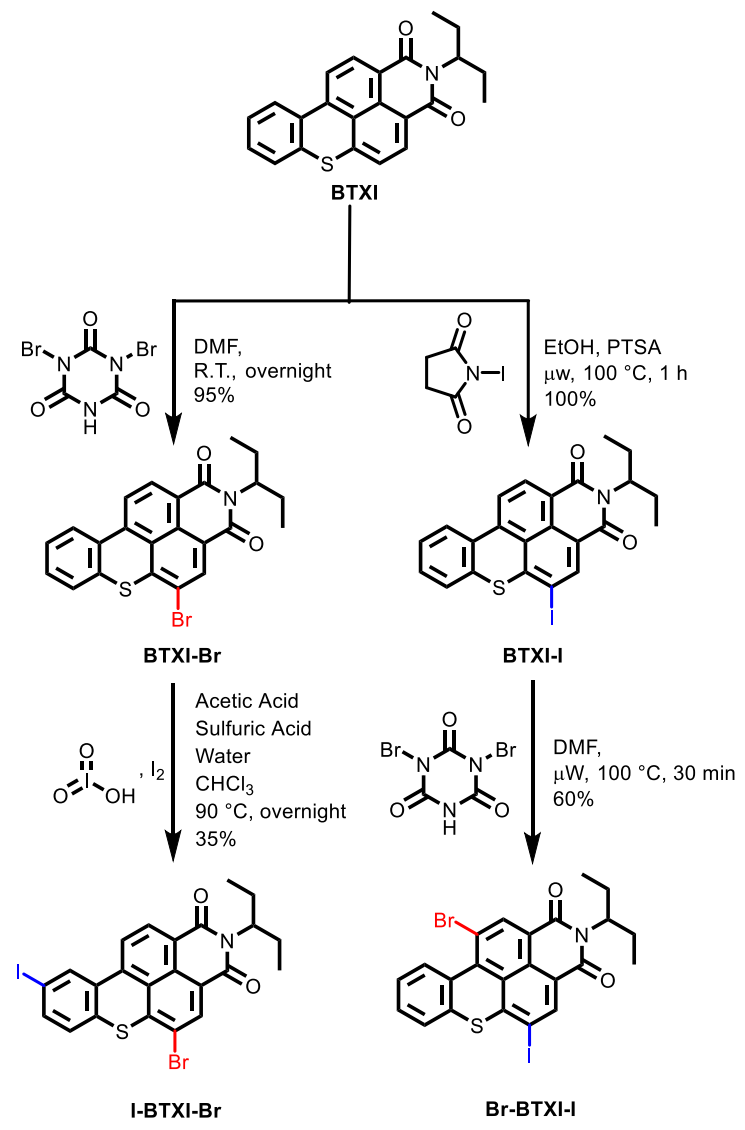

Figure 6. X-ray structures of I-BTXI-Br (left) and Br-BTXI-I (right).
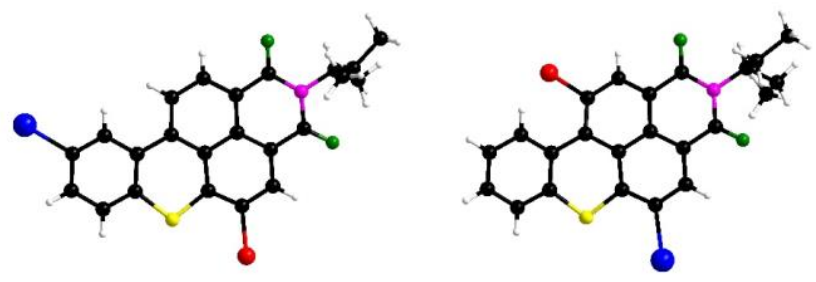

\section{Conclusion}

In conclusion, the regioselective dihalogenation of the BTXI core is demonstrated herein. As a result, five new derivatives were successfully prepared, isolated and characterized. Depending on the nature and source of the halogen atom, different positions on the rylene core are now fully and, above all, selectively accessible for post grafting purposes, thus opening doors to new designs of functional $\pi$-conjugated BTXI based molecules and polymers. 


\section{Experimental Section \\ Supporting Information}

\section{Acknowledgements}

Authors thank the MATRIX SFR of the University of Angers. J.M.A.C. and P.S.M. thanks the European Union's Horizon 2020 research and innovation program under Marie Sklodowska Curie Grant agreement No.722651 (SEPOMO). The Région Pays de la Loire is also acknowledged for the grant of C. D. (Projet étoile montante SAMOA). The authors are also grateful to ANR (SADAM ANR-16-CE07-0015-01) for financial support and the PDF grant of L.A.G.

Keywords: selective halogenation $\bullet$ benzothioxanthene $\bullet$ organic chemistry $\bullet$ rylene

\section{References}

1. Feng, J.; Jiang, W.; Wang, Z., Synthesis and Application of Rylene Imide Dyes as Organic Semiconducting Materials. Chemistry - An Asian Journal 2018, 13 (1), 20-30.

2. $\quad$ Sun, M.; Müllen, K.; Yin, M., Water-soluble perylenediimides: design concepts and biological applications. Chemical Society Reviews 2016, 45 (6), 1513-1528.

3. Zhang, F.; Ma, Y.; Chi, Y.; Yu, H.; Li, Y.; Jiang, T.; Wei, X.; Shi, J., Self-assembly, optical and electrical properties of perylene diimide dyes bearing unsymmetrical substituents at bay position. Scientific Reports 2018, 8 (1), 8208.

4. Kozma, E.; Catellani, M., Perylene diimides based materials for organic solar cells. Dyes and Pigments 2013, 98 (1), 160-179.

5. $\quad$ Würthner, F.; Saha-Möller, C. R.; Fimmel, B.; Ogi, S.; Leowanawat, P.; Schmidt, D., Perylene Bisimide Dye Assemblies as Archetype Functional Supramolecular Materials. Chemical Reviews 2016, $116(3), 962-1052$.

6. Liu, Z.; Wu, Y.; Zhang, Q.; Gao, X., Non-fullerene small molecule acceptors based on perylene diimides. Journal of Materials Chemistry A 2016, 4 (45), 17604-17622.

7. Andrés Castán, J. M.; Abad Galán, L.; Li, S.; Dalinot, C.; Simón Marqués, P.; Allain, M.; Risko, C.; Monnereau, C.; Maury, O.; Blanchard, P.; Cabanetos, C., Nitration of benzothioxanthene: towards a new class of dyes with versatile photophysical properties. New Journal of Chemistry 2020, 44 (3), 900 905.

8. Grayshan, P. H.; Kadhim, A. M.; Perters, A. T., Heterocyclic derivalives of naphthalene-1,8-dicar boxylie anhydride. Part III. Benzo[k,1] thioxanthene-3,4-dicarboximides. Journal of Heterocyclic Chemistry 1974, 11 (1), 33-38.

9. Kadhim, A. M.; Peters, A. T., A new intramolecular cyclisation reaction-I: Novel synthesis of benzo(k,1)thioxanthene-3,4-dicarboxylic anhydride and derived dyestuffs. Tetrahedron 1974, 30 (14), 2245-2249.

10. Danko, M.; Chmela, Š.; Hrdlovič, P., Synthesis, photochemical stability and photo-stabilizing efficiency of probes based on benzothioxanthene chromophore and Hindered Amine Stabilizer. Polymer Degradation and Stability 2006, 91 (5), 1045-1051.

11. Mao, P.; Qian, X.; Zhang, H.; Yao, W., Benzothioxanthene dyes as fluorescent label for DNA hybridization: synthesis and application. Dyes and Pigments 2004, 60 (1), 9-16.

12. Zhang, W.; Chen, M.; Ling Wu, Y.; Tanaka, Y.; Juan Ji, Y.; Lin Zhang, S.; He Wei, C.; Xu, Y., Formation and stabilization of the telomeric antiparallel G-quadruplex and inhibition of telomerase by novel benzothioxanthene derivatives with anti-tumor activity. Scientific Reports 2015, 5 (1), 13693. 13. Josse, P.; Li, S.; Dayneko, S.; Joly, D.; Labrunie, A.; Dabos-Seignon, S.; Allain, M.; Siegler, B.; Demadrille, R.; Welch, G. C.; Risko, C.; Blanchard, P.; Cabanetos, C., Bromination of the benzothioxanthene Bloc: toward new $\pi$-conjugated systems for organic electronic applications. Journal of Materials Chemistry C 2018, 6 (4), 761-766. 
14. Payne, A.-J.; Rice, N. A.; McAfee, S. M.; Li, S.; Josse, P.; Cabanetos, C.; Risko, C.; Lessard, B. H.; Welch, G. C., Donor or Acceptor? How Selection of the Rylene Imide End Cap Impacts the Polarity of $\pi$-Conjugated Molecules for Organic Electronics. ACS Applied Energy Materials 2018, 1 (9), 4906-4916. 15. Dayneko, S. V.; Hendsbee, A. D.; Cann, J. R.; Cabanetos, C.; Welch, G. C., Ternary organic solar cells: using molecular donor or acceptor third components to increase open circuit voltage. New Journal of Chemistry 2019, 43 (26), 10442-10448.

16. Grolleau, J.; Frère, P.; Gohier, F., Clean and Efficient Iodination of Thiophene Derivatives. Synthesis 2015, 47 (24), 3901-3906.

17. Bose, A.; Mal, P., Electrophilic aryl-halogenation using N-halosuccinimides under ball-milling. Tetrahedron Letters 2014, 55 (13), 2154-2156. 
Regioselective mono and homohetero dihalogenation of th... (1.00 MiB) view on ChemRxiv - download file 


\section{Supplementary Information}

\section{Regioselective mono and homo/hetero dihalogenation of the benzothioxanthene monoimide}

Clément Dalinot, ${ }^{[a]}$ Pablo Simón Marqués, ${ }^{[a]}$ José M. Andrés Castán, ${ }^{[a]}$ Pierre Josse, ${ }^{[a]}$ Magali Allain, ${ }^{[a]}$ Laura Abad Galán, ${ }^{[b]}$ Cyrille Monnereau, ${ }^{[b]}$ Olivier Maury, ${ }^{[b]}$ Philippe Blanchard, ${ }^{[a]}$ Clément Cabanetos*[a]
[a]
MOLTECH-Anjou, CNRS UMR 6200, University of Angers, 2 Bd Lavoisier, 49045, France
E-mail: clement.cabanetos@univ-angers.fr
[b] Univ Lyon, ENS de Lyon, CNRS UMR 5182, Université Claude Bernard Lyon 1, F-69342 Lyon, France

\section{Table of contents}

General methods

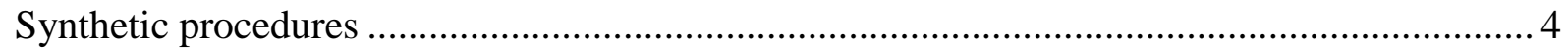

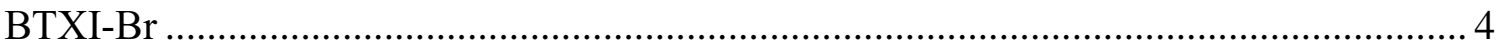

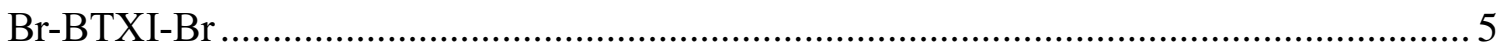

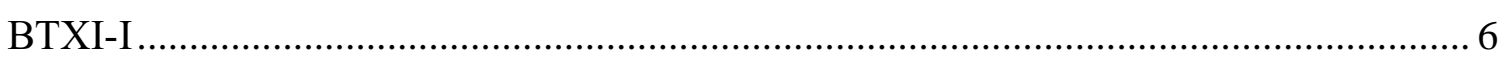

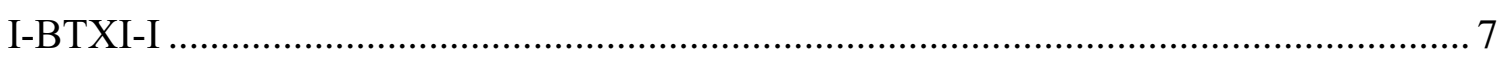

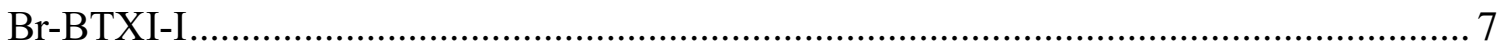

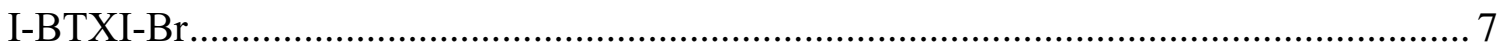

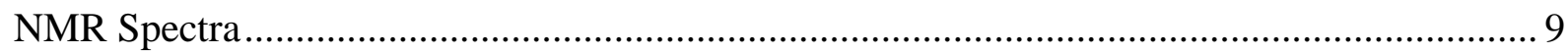

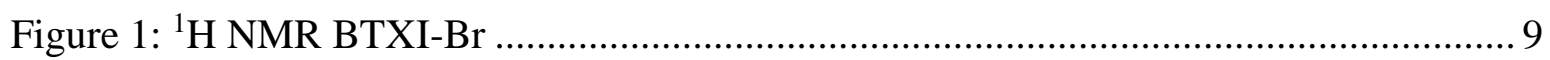

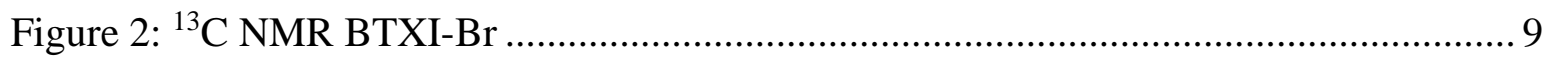

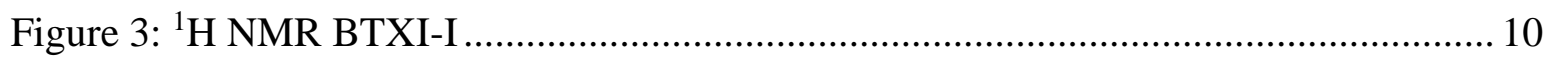

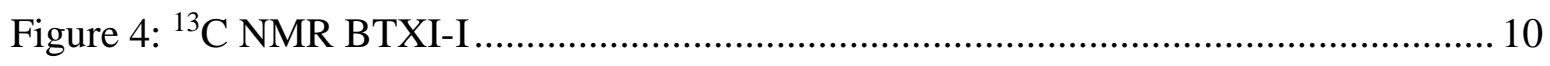

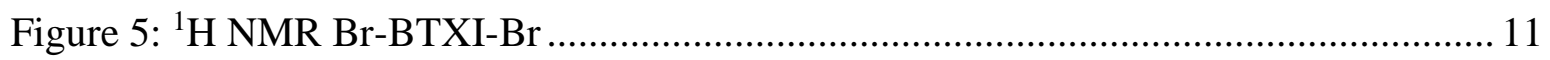

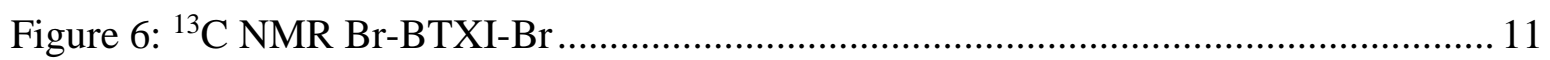

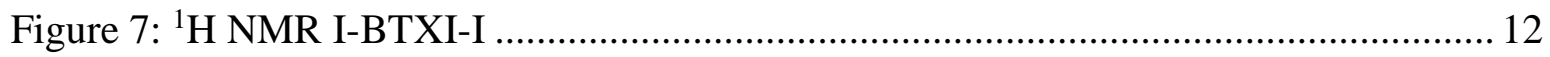

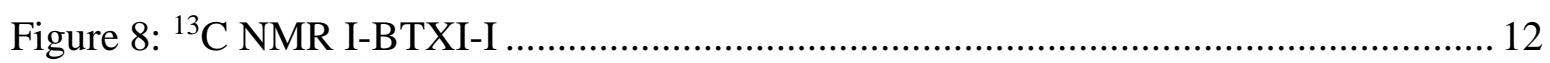

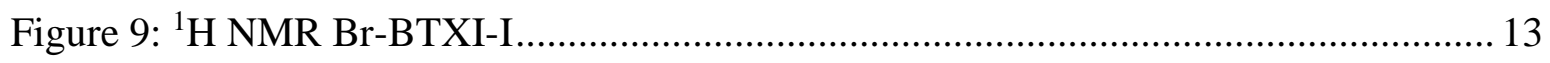

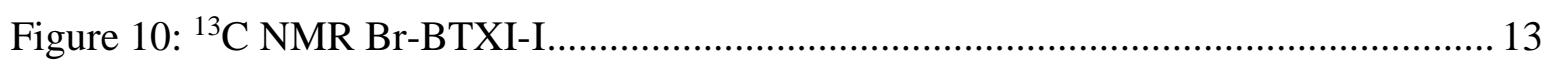

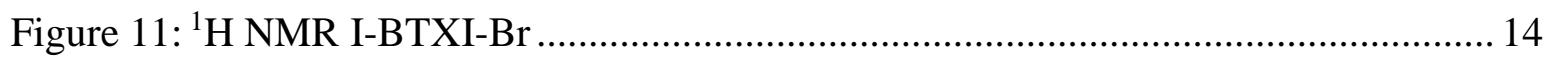

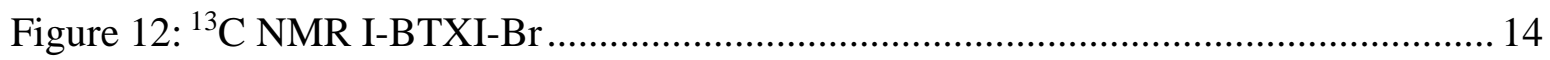

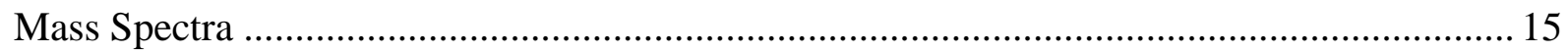

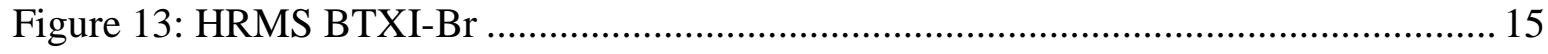

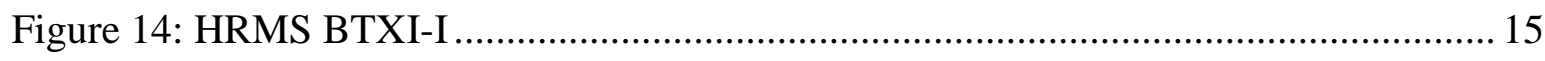


Figure 15: HRMS Br-BTXI-Br 16

Figure 16: HRMS Br-BTXI-I. 16

Figure 17: HRMS I-BTXI-Br. 17

Figure 18: HRMS I-BTXI-I 17

Crystallographic data. 18 


\section{General methods}

All reagents and solvents were purchased from commercial sources and used without further purification. Purifications by chromatography were performed with analytical-grade solvents using Aldrich silica gel (technical grade, pore size $60 \AA, 230-400$ mesh particle size). Flexible plates ALUGRAM $^{\circledR}$ XtraSIL G UV254 from MACHEREY-NAGEL were used for thin layer chromatography (TLC). ${ }^{1} \mathrm{H}$ and ${ }^{13} \mathrm{C}$ nuclear magnetic resonance (NMR) were recorded on a Bruker AVANCE III $300\left({ }^{1} \mathrm{H}, 300 \mathrm{MHz} ;{ }^{13} \mathrm{C}, 75 \mathrm{MHz}\right)$ or a Bruker AVANCE DRX500 $\left({ }^{1} \mathrm{H}, 500 \mathrm{MHz}\right.$ $;{ }^{13} \mathrm{C}, 125 \mathrm{MHz}$ ). Chemical shifts are given in ppm relative to tetramethylsilane (TMS) and coupling constants J in Hertz (Hz). Matrix Assisted Laser Desorption/lonization was performed on MALDI-TOF MS BIFLEX III Bruker Daltonics spectrometer or with a JEOL Spiral-TOF JMS3000. Microwave assisted reactions were performed with a biotage initiator ${ }^{+}$system. Ball-milling technique was performed with a RETSCH MM400 with a frequency of $30 \mathrm{~Hz} . \mathrm{s}^{-1}$. X-ray singlecrystal diffraction data were collected on a Rigaku Oxford Diffraction SuperNova diffractometer equipped with Atlas CCD detector and micro-focus Cu-K $\alpha$ radiation (1.54184 $\AA$ ). The structures were solved by direct methods and refined on F2 by full matrix least-squares techniques using SHELX programs (G. M. Sheldrick, 2018). All non-H atoms were refined anisotropically and multiscan empirical absorption was corrected using CrysAlisPro program (CrysAlisPro, Agilent Technologies, V 1.171.40.45a, 2019). The $\mathrm{H}$ atoms were included in the calculation without refinement. 


\section{Synthetic procedures}

\section{5-bromo-2-(pentan-3-yl)-1H-thioxantheno[2,1,9-def]isoquinoline-1,3(2H)-dione (BTXI-Br)}

Entry 1, Table 1: To a solution of 2-(pentan-3-yl)-1H-thioxantheno[2,1,9-def]isoquinoline1,3(2H)-dione (BTXI) $(700 \mathrm{mg}, 1.87 \mathrm{mmol})$ in $\mathrm{CH}_{2} \mathrm{Cl}_{2}(100 \mathrm{~mL})$ was added dropwise a solution of bromine (1.1 eq, $94 \mathrm{mmL}, 2.06 \mathrm{mmol})$ in $\mathrm{CH}_{2} \mathrm{Cl}_{2}(40 \mathrm{~mL})$. The reaction mixture was stirred overnight at room temperature before being subsequently washed with a saturated aqueous solution of $\mathrm{Na}_{2} \mathrm{~S}_{2} \mathrm{O}_{3}$, water and brine. Once dried over $\mathrm{MgSO}_{4}$, the solvent was removed by rotary evaporation and the crude was subsequently subjected to silica gel column chromatography using toluene as eluent to give the target compound as an orange solid in $93 \%$ yield (784 mg).REF

Entries 2-3, Table 1: $N$-bromosuccinimide $(95 \mathrm{mg}, 535 \mu \mathrm{mol}))$ was added to a solution of 2(pentan-3-yl)-1H-thioxantheno[2,1,9-def] isoquinoline-1,3(2H)-dione (BTXI) (50 mg, $133 \mu \mathrm{mol}$ ) in either chloroform or $\mathrm{N}, \mathrm{N}$-dimethylformamide $(20 \mathrm{~mL})$ at room temperature. After a night of stirring, the crude was analyzed mass spectrometry revealing the absence of reactivity since only the starting material (BTXI) was detected.

Entries 4-5, Table 1: $N$-bromosuccinimide (95 mg, $535 \mu \mathrm{mol})$ ) was added to a solution of 2(pentan-3-yl)-1H-thioxantheno[2,1,9-def]isoquinoline-1,3(2H)-dione (BTXI) (50 mg, $133 \mu \mathrm{mol}$ ) in either chloroform or $N, N$-dimethylformamide $(20 \mathrm{~mL})$ at room temperature. After a night under reflux, the crude was analyzed mass spectrometry once again revealing the absence of reactivity since only the starting material (BTXI) was detected.

Entry 6, Table 1: In a $20 \mathrm{~mL}$ microwave vial with a stir-bar 2-(pentan-3-yl)-1Hthioxantheno[2,1,9-def] isoquinoline-1,3(2H)-dione (BTXI) $(50 \mathrm{mg}, 133 \mu \mathrm{mol})$ and $\mathrm{N}$ bromosuccinimide (NBS, 4.0 eq, $95 \mathrm{mg}, 535 \mu \mathrm{mol}$ ) were suspended in EtOH (10 mL). The vial was sealed with a cap and the mixture was heated under microwave irradiation for $15 \mathrm{~min}$ at a pre-selected temperature of $100{ }^{\circ} \mathrm{C}$. Then, the crude was then poured into $\mathrm{CH}_{2} \mathrm{Cl}_{2}$ and the organic layer was subsequently washed with a saturated aqueous solution of $\mathrm{Na}_{2} \mathrm{~S}_{2} \mathrm{O}_{3}$, water and brine. Once dried over $\mathrm{MgSO}_{4}$, the solvent was removed by rotary evaporation and the crude was subjected to silica gel column chromatography using toluene as eluent to give the target compound as an orange solid in $11 \%$ yield $(7 \mathrm{mg})$.

General procedure for entries 7-9, Table 1: 2-(pentan-3-yl)-1H-thioxantheno[2,1,9def]isoquinoline-1,3(2H)-dione (BTXI) $(100 \mathrm{mg}, 267 \mu \mathrm{mol})$ and $\mathrm{N}$-bromosuccinimide were transferred into a milling vessel $(5 \mathrm{~mL}$, stainless steel). Once the $5 \mathrm{~mm}$ stainless steel ball added, the ball-milling process was carried out over an hour. Thereafter, the milling vessel was washed with crude $\mathrm{CH}_{2} \mathrm{Cl}_{2}$ and the resulting organic layer was washed with a saturated aqueous solution of $\mathrm{Na}_{2} \mathrm{~S}_{2} \mathrm{O}_{3}$, water and brine. Once dried over $\mathrm{MgSO}_{4}$, the solvent was removed by rotary evaporation and the crude was subjected to silica gel column chromatography using toluene as eluent to give the target compound as an orange solid. Entry 7: $42 \mathrm{mg}, 33 \%$. Entry 8: $76 \mathrm{mg}, 60 \%$. Entry 9: $126 \mathrm{mg}, 99 \%$ 
Entry 10, Table 1: 2-(pentan-3-yl)-1H-thioxantheno[2,1,9-def]isoquinoline-1,3(2H)-dione (BTXI) $(20 \mathrm{mg}, 53 \mu \mathrm{mol})$ and dibromoisocyanuric acid (1.1 eq, $17 \mathrm{mg}, 59 \mu \mathrm{mol}$ ) were suspended in DMF (4 mL). The reaction mixture was stirred overnight at room temperature. Then the crude was poured into EtOAc and the organic layer was washed with a saturated aqueous solution of $\mathrm{Na}_{2} \mathrm{~S}_{2} \mathrm{O}_{3}$, water and brine. Once dried over $\mathrm{MgSO}_{4}$, the solvent was removed by rotary evaporation and the crude was subjected to silica gel column chromatography using toluene as eluent to give the target compound as an orange solid in $95 \%$ yield ( $23 \mathrm{mg}$ ).

Entry 11, Table 1: 2-(pentan-3-yl)-1H-thioxantheno[2,1,9-def]isoquinoline-1,3(2H)-dione (BTXI) $(100 \mathrm{mg}, 267 \mu \mathrm{mol})$ and pyridinium tribromide (1.1 eq, $94 \mathrm{mg}, 294 \mu \mathrm{mol})$ were solubilized in $\mathrm{CH}_{2} \mathrm{Cl}_{2}(10 \mathrm{~mL})$. The reaction mixture was stirred overnight at room temperature before being washed with a saturated aqueous solution of $\mathrm{Na}_{2} \mathrm{~S}_{2} \mathrm{O}_{3}$, water and brine. Once dried over $\mathrm{MgSO}_{4}$, the solvent was removed by rotary evaporation and the crude was subjected to silica gel column chromatography using toluene as eluent to give the target compound as an orange solid in $47 \%$ yield $(57 \mathrm{mg}$ ).

General procedure for entries 12-13, Table 1: 2-(pentan-3-yl)-1H-thioxantheno[2,1,9def]isoquinoline-1,3(2H)-dione (BTXI) $(100 \mathrm{mg}, 267 \mu \mathrm{mol})$ and pyridinium tribromide (1.1 eq or $2.2 \mathrm{eq})$ were transferred in a $20 \mathrm{~mL}$ microwave vial before being solubilized in $\mathrm{CH}_{2} \mathrm{Cl}_{2}(10$ $\mathrm{mL}$ ). The mixture was heated under microwave irradiation for 1 hour at a pre-selected temperature of $100{ }^{\circ} \mathrm{C}$. Upon completion, the organic layer was removed by rotary evaporation and the crude was directly subjected to silica gel column chromatography using toluene as eluent to afford the target compound (BTXI-Br) as an orange solid. Entry 10: 52\%,

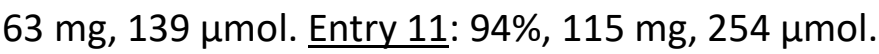

${ }^{1} \mathbf{H}$ NMR (300 MHz, Chloroform-d): $\delta 8.62(\mathrm{~m}, 2 \mathrm{H}), 8.29-8.22(\mathrm{~m}, 2 \mathrm{H}), 7.52-7.43(\mathrm{~m}, 3 \mathrm{H}), 5.09$ $-4.99(\mathrm{~m}, 1 \mathrm{H}), 2.32-2.17(\mathrm{~m}, 2 \mathrm{H}), 1.97-1.84(\mathrm{~m}, 2 \mathrm{H}), 0.89(\mathrm{t}, \mathrm{J}=7.5,6 \mathrm{H}) .{ }^{13} \mathrm{C} \mathrm{NMR}(125 \mathrm{MHz}$, Chloroform-d): $\delta$ 140.0, 135.9, 134.6, 132.1, 131.6, 130.1, 129.1, 128.0, 127.4, 127.8, 126.6, 125.7, 121.7, 119.8, 119.0, 114.5, 57.7, 25.0, 11.5. HRMS (EI): calculated for $\mathrm{C}_{23} \mathrm{H}_{18} \mathrm{BrNO}_{2} \mathrm{~S}$ 451.0242 , found 451.0246 .

5,11-dibromo-2-(pentan-3-yl)-1H-thioxantheno[2,1,9-def]isoquinoline-1,3(2H)-dione

$(\mathrm{Br}-$ BTXI-Br)

General procedure for entries 1-3, Table 2:, 2-(pentan-3-yl)-1H-thioxantheno[2,1,9def]isoquinoline-1,3(2H)-dione (BTXI) $(100 \mathrm{mg}, 267 \mu \mathrm{mol})$ and pyridinium tribromide (5.0 eq, 10.0 eq or 20.0 eq) were transferred in a $20 \mathrm{~mL}$ microwave vial before being solubilized in $\mathrm{CH}_{2} \mathrm{Cl}_{2}(10 \mathrm{~mL})$. The mixture was then heated under microwave irradiation for 1 hour at a preselected temperature of $100{ }^{\circ} \mathrm{C}$. Upon completion, the organic layer was removed by rotary evaporation and the crude was directly subjected to silica gel column chromatography using toluene as eluent. Entry 1: 5\%, $7 \mathrm{mg}, 13 \mu \mathrm{mol}$. Entry 2: 11\%, $16 \mathrm{mg}, 30 \mu \mathrm{mol}$. Entry 3: 12\%, 17 $\mathrm{mg}, 32 \mu \mathrm{mol}$. 
General procedure for entries 4-5, Table 2: 2-(pentan-3-yl)-1H-thioxantheno[2,1,9def lisoquinoline-1,3(2H)-dione (BTXI) $(50 \mathrm{mg}, 133 \mu \mathrm{mol})$ and dibromoisocyanuric acid (2.2 eq or 5 eq) were suspended in DMF $(10 \mathrm{~mL})$. The reaction mixture was stirred overnight at 150 ${ }^{\circ} \mathrm{C}$. Then, the crude was poured into EtOAc and the organic layer was washed with a saturated aqueous solution of $\mathrm{Na}_{2} \mathrm{~S}_{2} \mathrm{O}_{3}$, water and brine. Once dried over $\mathrm{MgSO}_{4}$, the solvent was removed by rotary evaporation and the crude was subjected to silica gel column chromatography using $\mathrm{CH}_{2} \mathrm{Cl}_{2}$ as eluent. Entry 4: 32\%, $23 \mathrm{mg}, 43 \mu \mathrm{mol}$. Entry 5: 18\%, $13 \mathrm{mg}, 24$ umol.

General procedure for entries 6-8, Table 2: Bromine (5.0 eq, 10.0 eq or 20.0 eq) was directly added to a solution of 2-(pentan-3-yl)-1H-thioxantheno[2,1,9-def] isoquinoline-1,3(2H)-dione (BTXI) in $\mathrm{CH}_{2} \mathrm{Cl}_{2}(4 \mathrm{~mL})$. The reaction mixture was refluxed overnight before being washed with a saturated aqueous solution of $\mathrm{Na}_{2} \mathrm{~S}_{2} \mathrm{O}_{3}$, water and brine. Once dried over $\mathrm{MgSO}_{4}$, the solvent was removed by rotary evaporation and the crude was subjected to silica gel column chromatography using toluene as eluent. Entry 6: 19\%, $14 \mathrm{mg}, 26 \mu \mathrm{mol}$. Entry 7: 73\%, $52 \mathrm{mg}$, $98 \mu \mathrm{mol}$. Entry 8: 98\%, $70 \mathrm{mg}, 131 \mu \mathrm{mol}$.

${ }^{1} \mathrm{H}$ NMR (500 MHz, Chloroform-d): $\delta 8.85(\mathrm{~s}, 1 \mathrm{H}), 8.70$ (dd, J = 8.2, $\left.1.4 \mathrm{~Hz}, 1 \mathrm{H}\right), 8.63(\mathrm{~s}, 1 \mathrm{H})$, 7.57 (dd, J = 7.7, $1.5 \mathrm{~Hz}, 1 \mathrm{H}$ ), $7.47(\mathrm{td}, \mathrm{J}=7.5,1.4 \mathrm{~Hz}, 1 \mathrm{H}), 7.42$ (td, J = 7.9, 7.5, $1.5 \mathrm{~Hz}, 1 \mathrm{H}$ ), 5.01 $(\mathrm{m}, 1 \mathrm{H}), 2.22(\mathrm{~m}, 2 \mathrm{H}), 1.95-1.83(\mathrm{~m}, 2 \mathrm{H}), 0.88(\mathrm{t}, \mathrm{J}=7.5 \mathrm{~Hz}, 6 \mathrm{H}) .{ }^{13} \mathrm{C}$ NMR $(125 \mathrm{MHz}$, Chloroform-d): $\delta$ 139.2, 136.8, 133.1, 131.2, 130.7, 130.3, 128.3, 127.3, 127.1, 126.8, 117.9, 116.1, 58.0, 25.0, 11.4. HRMS (EI): calculated for $\mathrm{C}_{23} \mathrm{H}_{17} \mathrm{Br}_{2} \mathrm{NO}_{2} \mathrm{~S}$ : 528.9347, found 528.9352. Monocrystal was obtained by slow evaporation of toluene.

5-iodo-2-(pentan-3-yl)-1H-thioxantheno[2,1,9-def] isoquinoline-1,3(2H)-dione (BTXI-I)

Entry 1, Table 3: 2-(pentan-3-yl)-1H-thioxantheno[2,1,9-def]isoquinoline-1,3(2H)-dione (BTXI) (20 mg, $53 \mu \mathrm{mol}), p$-toluenesulfonic acid $(922 \mu \mathrm{g}, 5.36 \mu \mathrm{mol})$ and $\mathrm{N}$-iodosuccinimide (NIS, 2.0 eq, $24 \mathrm{mg}, 107 \mu \mathrm{mol})$ were suspended in $\mathrm{EtOH}(10 \mathrm{~mL})$. The reaction mixture was stirred overnight at $60{ }^{\circ} \mathrm{C}$. Then, the crude product was poured into $\mathrm{CH}_{2} \mathrm{Cl}_{2}$ and washed with a saturated aqueous solution of $\mathrm{Na}_{2} \mathrm{~S}_{2} \mathrm{O}_{3}$, water and brine. Once dried over $\mathrm{MgSO}_{4}$, the solvent was removed by rotary evaporation and the crude was subjected to silica gel column chromatography using toluene as eluent to afford the target compound (BTXI-I) as an orange solid in $67 \%$ yield $(18 \mathrm{mg})$.

General procedure for entries 2-3, Table 3: 2-(pentan-3-yl)-1H-thioxantheno[2,1,9def lisoquinoline-1,3(2H)-dione (BTXI) $(50 \mathrm{mg}, 133 \mu \mathrm{mol}), p$-toluenesulfonic acid $(2.31 \mathrm{mg}, 13$ $\mu \mathrm{mol}$ ) and $\mathrm{N}$-iodosuccinimide (NIS, 2.0 eq or $4.0 \mathrm{eq}$ ) were transferred in a $20 \mathrm{~mL}$ microwave vial before being suspended in $10 \mathrm{~mL}$ of EtOH. The reaction mixture was then heated under microwave irradiation for 1 hour at a pre-selected temperature of $100{ }^{\circ} \mathrm{C}$. Upon completion, the organic layer was removed by rotary evaporation and the crude was directly subjected to silica gel column chromatography using toluene as eluent to afford the target compound (BTXII) as an orange solid. Entry 2: 80\%, $54 \mathrm{mg}$. Entry 3: 100\% yield, $67 \mathrm{mg}$. 
${ }^{1} \mathrm{H}$ NMR (300 MHz, Chloroform-d): $\delta 8.82(\mathrm{~s}, 1 \mathrm{H}), 8.61(\mathrm{~d}, J=8.2 \mathrm{~Hz}, 1 \mathrm{H}), 8.26-8.19(\mathrm{~m}, 2 \mathrm{H})$, $7.53-7.37(\mathrm{~m}, 3 \mathrm{H}), 5.04(\mathrm{~m}, 1 \mathrm{H}), 2.24(\mathrm{~m}, 2 \mathrm{H}), 1.91(\mathrm{~m}, 2 \mathrm{H}), 0.89(\mathrm{t}, J=7.5 \mathrm{~Hz}, 6 \mathrm{H}) .{ }^{13} \mathrm{C}$ NMR (76 MHz, Chloroform-d): $\delta 143.9,136.6,132.8,130.3,129.8,128.2,128.0,126.9,126.8,126.0$, 120.0, 88.7, 57.7, 25.0, 11.5. HRMS (El): calculated for $\mathrm{C}_{23} \mathrm{H}_{18} \mathrm{INO}_{2} \mathrm{~S}:$ 499.0103, found 499.0096. Monocrystal was obtained by slow evaporation of toluene.

5,9-diiodo-2-(pentan-3-yl)-1H-thioxantheno[2,1,9-def] isoquinoline-1,3(2H)-dione (I-BTXI-I) General procedure for entries 4-5, Table 3: To a stirred suspension of 2-(pentan-3-yl)-1Hthioxantheno[2,1,9-def] isoquinoline-1,3(2H)-dione (BTXI) in a mixture of acetic acid, concentrated sulphuric acid, water and $\mathrm{CHCl}_{3}$ ( $\mathrm{v} / \mathrm{v} 100 / 5 / 20 / 8$ respectively) were added iodine ( $2.5 \mathrm{eq}, 169 \mathrm{mg}, 669 \mu \mathrm{mol})$ and iodic acid $(0.5 \mathrm{eq}, 59 \mathrm{mg}, 334 \mu \mathrm{mol})$. The mixture was either stirred at room temperature (entry 4 ) or refluxed (entry 5 ) overnight. Then the mixture was cooled to room temperature and was poured into iced water, washed with a saturated aqueous solution of $\mathrm{Na}_{2} \mathrm{~S}_{2} \mathrm{O}_{3}$ and brine. Once dried over $\mathrm{MgSO}_{4}$, the solvent was removed by rotary evaporation and the crude was subjected to silica gel column chromatography using toluene as eluent. Entry 4: $5 \mathrm{mg}, 8 \mu \mathrm{mol}, 3 \%$. Entry 5: $130 \mathrm{mg}, 208 \mu \mathrm{mol}, 19 \%$.

${ }^{1} \mathrm{H}$ NMR (300 MHz, Chloroform-d): $\delta 8.83(\mathrm{~s}, 1 \mathrm{H}), 8.62(\mathrm{~d}, J=8.2 \mathrm{~Hz}, 1 \mathrm{H}), 8.50(\mathrm{~d}, J=1.7 \mathrm{~Hz}$, $1 \mathrm{H}), 8.16(\mathrm{~d}, J=8.2 \mathrm{~Hz}, 1 \mathrm{H}), 7.72(\mathrm{dd}, J=8.4,1.7 \mathrm{~Hz}, 1 \mathrm{H}), 7.19(\mathrm{~d}, J=8.4 \mathrm{~Hz}, 1 \mathrm{H}), 5.03(\mathrm{~s}, 1 \mathrm{H})$, $2.21(\mathrm{dd}, J=9.6,7.4 \mathrm{~Hz}, 2 \mathrm{H}), 2.01-1.83(\mathrm{~m}, 2 \mathrm{H}), 0.89(\mathrm{t}, J=7.5 \mathrm{~Hz}, 6 \mathrm{H}) .{ }^{13} \mathrm{C}$ NMR $(75 \mathrm{MHz}$, Chloroform-d): $\delta 138.8,134.9,134.8,132.5,130.0,128.0,126.9,120.3,92.8,89.1,57.8,25.01$, 11.4. HRMS (EI): calculated for $\mathrm{C}_{23} \mathrm{H}_{17} \mathrm{I}_{2} \mathrm{NO}_{2} \mathrm{~S}$ : 624.9069, found 624.9046. Monocrystal was obtained by slow evaporation of toluene.

11-bromo-5-iodo-2-(pentan-3-yl)-1H-thioxantheno[2,1,9-def] isoquinoline 1,3(2H)-dione (BrBTXI-I). 5-iodo-2-(pentan-3-yl)-1H-thioxantheno[2,1,9-def] isoquinoline-1,3(2H)-dione (BTXI-I) (30 mg, $60 \mu \mathrm{mol}$ ) and dibromoisocyanuric acid ( $68 \mathrm{mg}, 240 \mu \mathrm{mol}$ ) were transferred in a $10 \mathrm{~mL}$ microwave vial before being suspended in $5 \mathrm{~mL}$ off. The mixture was subsequenly heated under microwave irradiation for $30 \mathrm{~min}$ at a pre-selected temperature of $100{ }^{\circ} \mathrm{C}$. Then the crude was poured into EtOAc and the organic layer was washed with a saturated aqueous solution of $\mathrm{Na}_{2} \mathrm{~S}_{2} \mathrm{O}_{3}$, water and brine. Once dried over $\mathrm{MgSO}_{4}$, the solvent was removed by rotary evaporation and the crude was subjected to silica gel column chromatography using toluene as eluent to give the target compound as an orange solid in $60 \%$ yield ( $21 \mathrm{mg}$ ).

${ }^{1} \mathrm{H}$ NMR $(300 \mathrm{MHz}$, Chloroform- $d$ ): $\delta 8.85(\mathrm{~s}, 1 \mathrm{H}), 8.83(\mathrm{~s}, 1 \mathrm{H}), 8.67(\mathrm{dd}, J=7.8,1.7 \mathrm{~Hz}, 1 \mathrm{H})$, $7.58(\mathrm{dd}, J=7.8,1.6 \mathrm{~Hz}, 1 \mathrm{H}), 7.54-7.36(\mathrm{~m}, 2 \mathrm{H}), 5.00(\mathrm{~m}, 1 \mathrm{H}), 2.32-2.11(\mathrm{~m}, 2 \mathrm{H}), 1.99-1.79$ $(\mathrm{m}, 2 \mathrm{H}), 0.87(\mathrm{t}, J=7.5 \mathrm{~Hz}, 6 \mathrm{H}) .{ }^{13} \mathrm{C}$ NMR $(76 \mathrm{MHz}$, Chloroform-d): $\delta 142.8,140.6,138.7,137.0$, 133.9, 131.1, 130.3, 130.2, 128.5, 127.8, 126.0, 126.8, 117.6, 90.4, 58.0, 25.0, 11.4. HRMS (EI): calculated for $\mathrm{C}_{23} \mathrm{H}_{17} \mathrm{BrINO} \mathrm{S}_{2} \mathrm{~S}: 576.9208$, found 576.9196 . Monocrystal was obtained by slow evaporation of toluene.

5-bromo-11-iodo-2-(pentan-3-yl)-1H-thioxantheno[2,1,9-def] isoquinoline-1,3(2H)-dione (IBTXI-Br. To a stirred suspension of BTXT-Br $(100.0 \mathrm{mg}, 221 \mu \mathrm{mol})$ in a mixture of acetic acid $(20 \mathrm{~mL})$, concentrated sulphuric acid $(1 \mathrm{~mL})$, water $(4 \mathrm{~mL})$ and $\mathrm{CHCl}_{3}$ were added iodine $(78.5$ $\mathrm{mg}, 309 \mu \mathrm{mol})$ and iodic acid $(54.4 \mathrm{mg}, 309 \mu \mathrm{mol})$. After a night of stirring at $90^{\circ} \mathrm{C}$, the reaction 
mixture was cooled down to room temperature and poured into iced water, washed with a saturated aqueous solution of $\mathrm{Na}_{2} \mathrm{~S}_{2} \mathrm{O}_{3}$ and brine. Once dried over $\mathrm{MgSO}_{4}$, the solvent was removed by rotary evaporation and the crude was subjected to silica gel column chromatography using toluene as eluent to afford I-BTXI-Br as an orange solid in 35\% yield ( 45 $\mathrm{mg})$.

${ }^{1} \mathrm{H}$ NMR (300 MHz, Chloroform- $\left.d\right): \delta 8.63(\mathrm{~m}, 2 \mathrm{H}), 8.53(\mathrm{~d}, J=1.7 \mathrm{~Hz}, 1 \mathrm{H}), 8.21(\mathrm{~d}, J=8.3 \mathrm{~Hz}$, $1 \mathrm{H}), 7.73(\mathrm{dd}, J=8.4,1.7 \mathrm{~Hz}, 1 \mathrm{H}), 7.22(\mathrm{~d}, J=8.4 \mathrm{~Hz}, 1 \mathrm{H}), 5.03(\mathrm{~m}, 1 \mathrm{H}), 2.35-2.13(\mathrm{~m}, 2 \mathrm{H})$, $2.00-1.80(\mathrm{~m}, 2 \mathrm{H}), 0.89(\mathrm{t}, J=7.5 \mathrm{~Hz}, 6 \mathrm{H}) .{ }^{13} \mathrm{C}$ NMR (76 MHz, Chloroform-d): $\delta$ 138.8, 134.9, 134.7, 131.6, 129.7, 129.3, 128.3, 127.1, 120.4, 115.0, 92.8, 57.8, 25.0, 11.4. HRMS (FAB-neg): calc. for $\mathrm{C}_{23} \mathrm{H}_{17} \mathrm{BrINO}_{2} \mathrm{~S}$ : 576.9208 , found 576.9205 . Monocrystal was obtained by slow evaporation of toluene. 


\section{NMR Spectra}

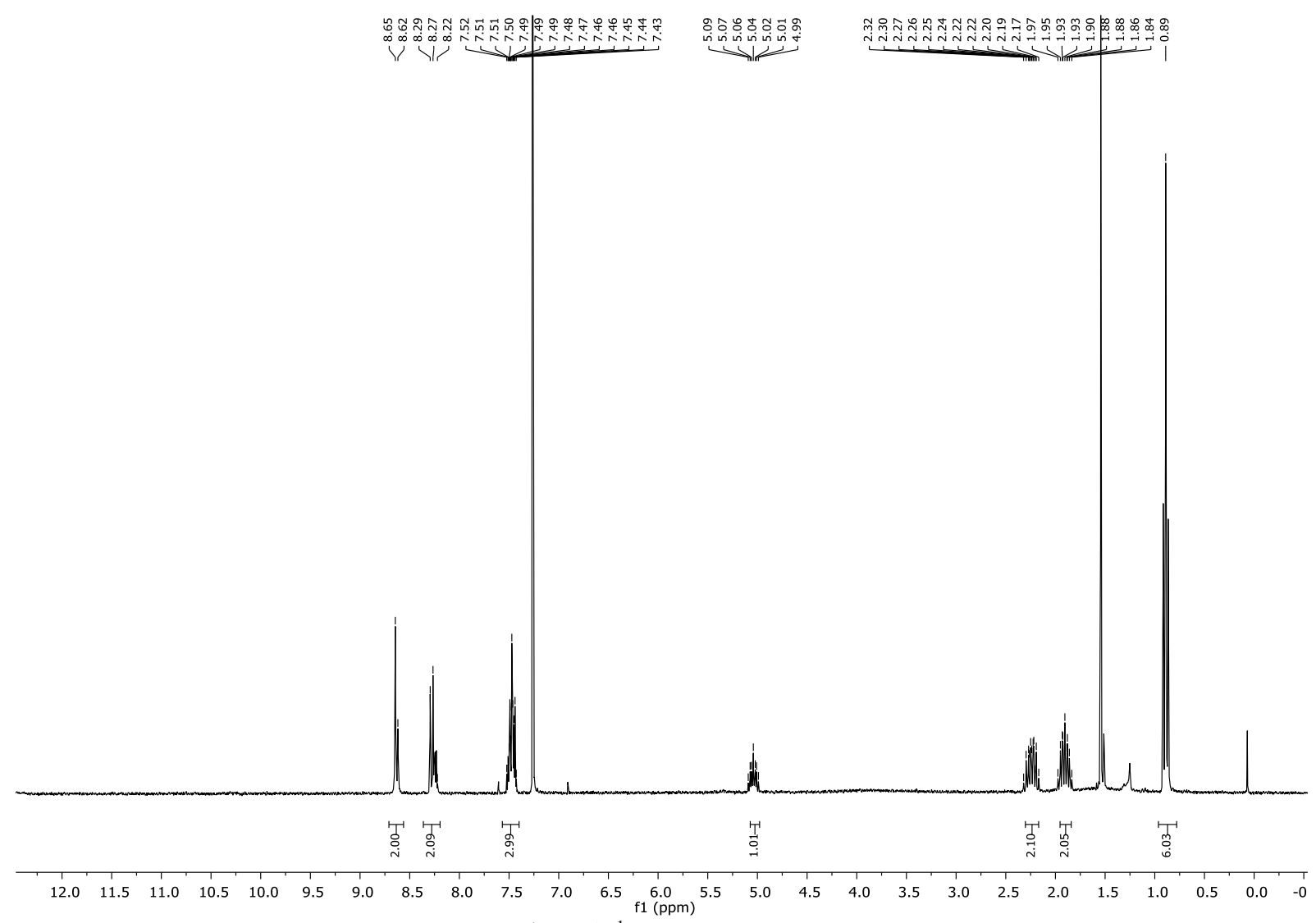

Figure 1: ${ }^{1} \mathrm{H}$ NMR BTXI-Br
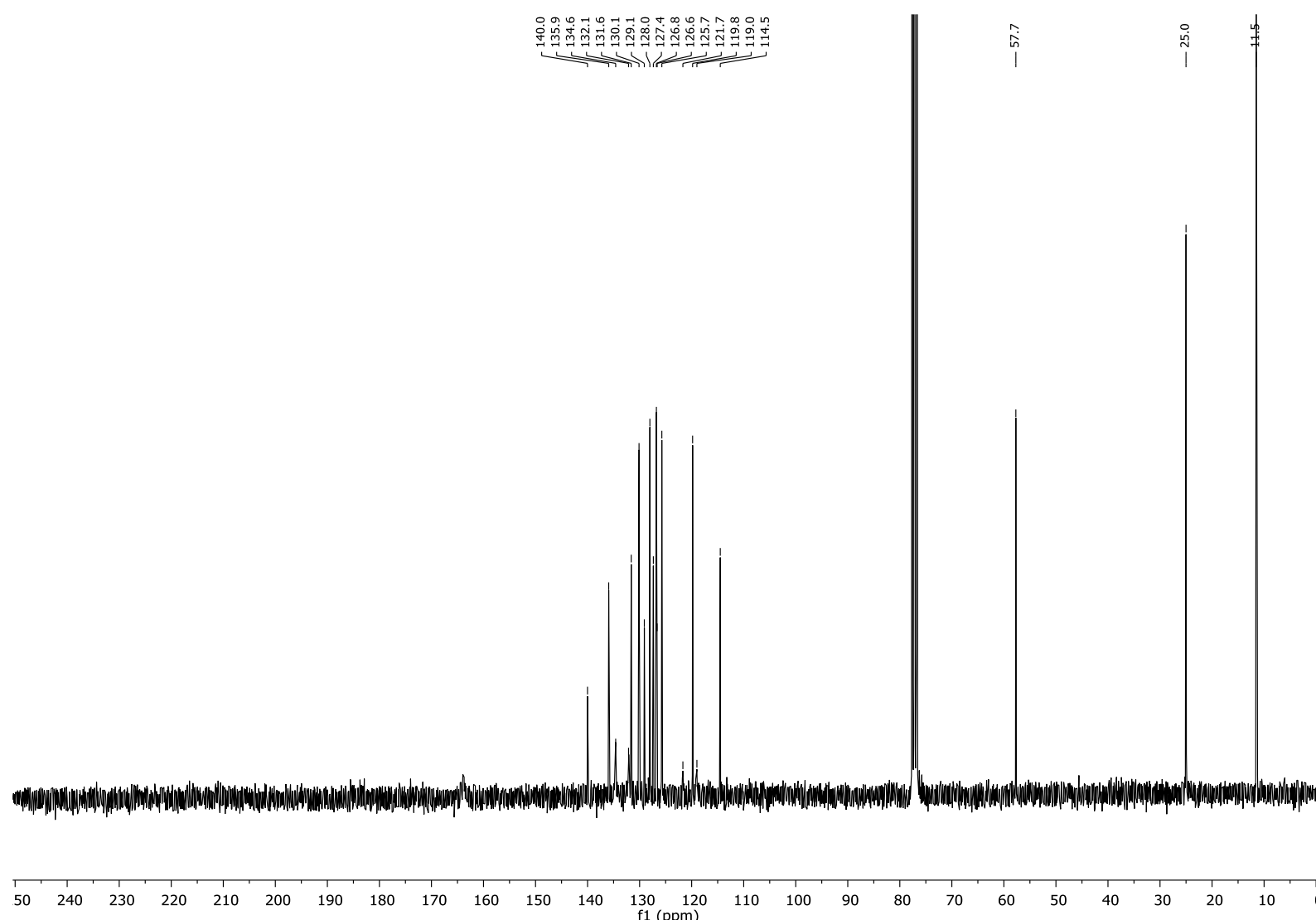

Figure 2: ${ }^{13} \mathrm{C}$ NMR BTXI-Br 


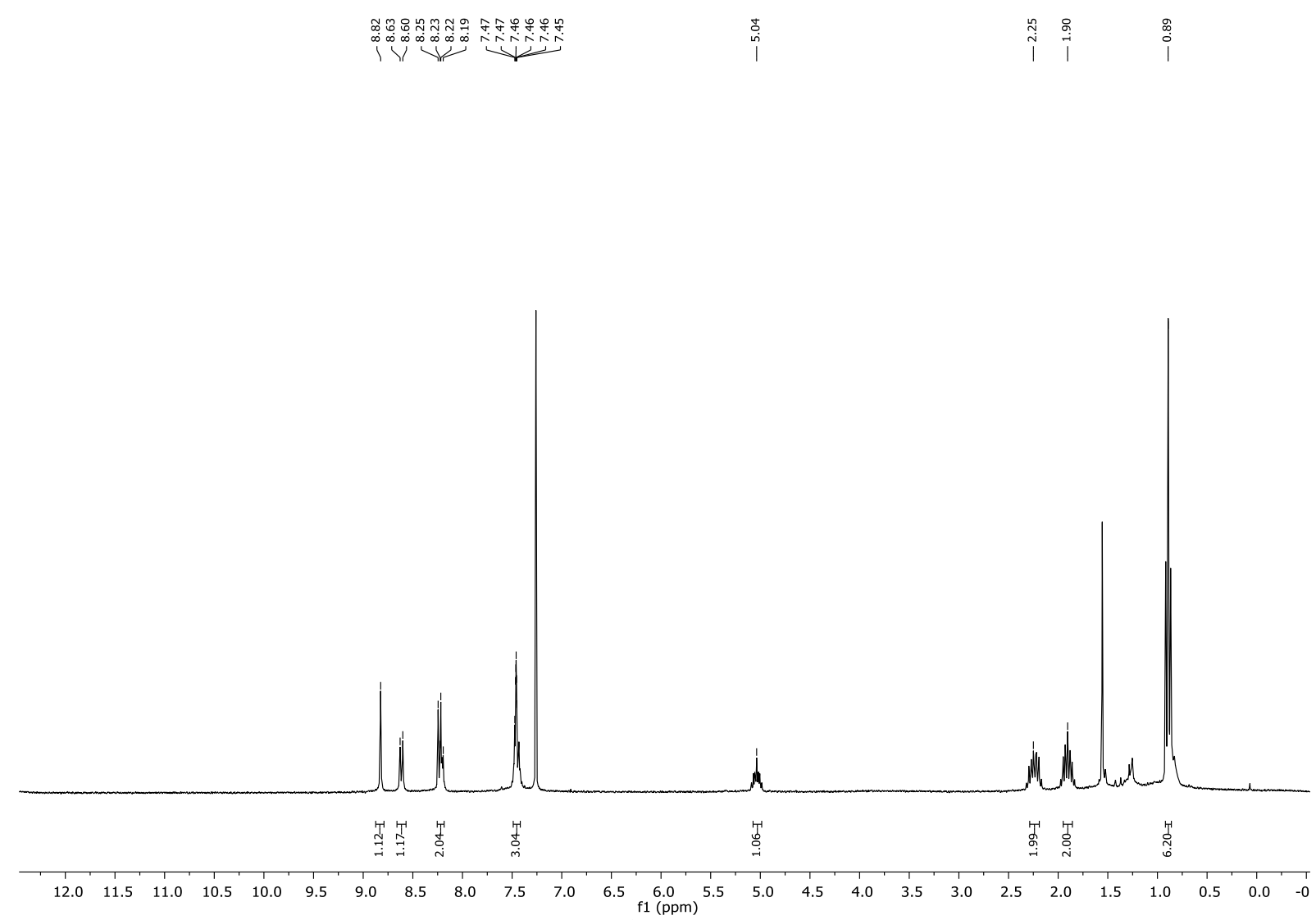

Figure 3: ${ }^{1} \mathrm{H}$ NMR BTXI-I

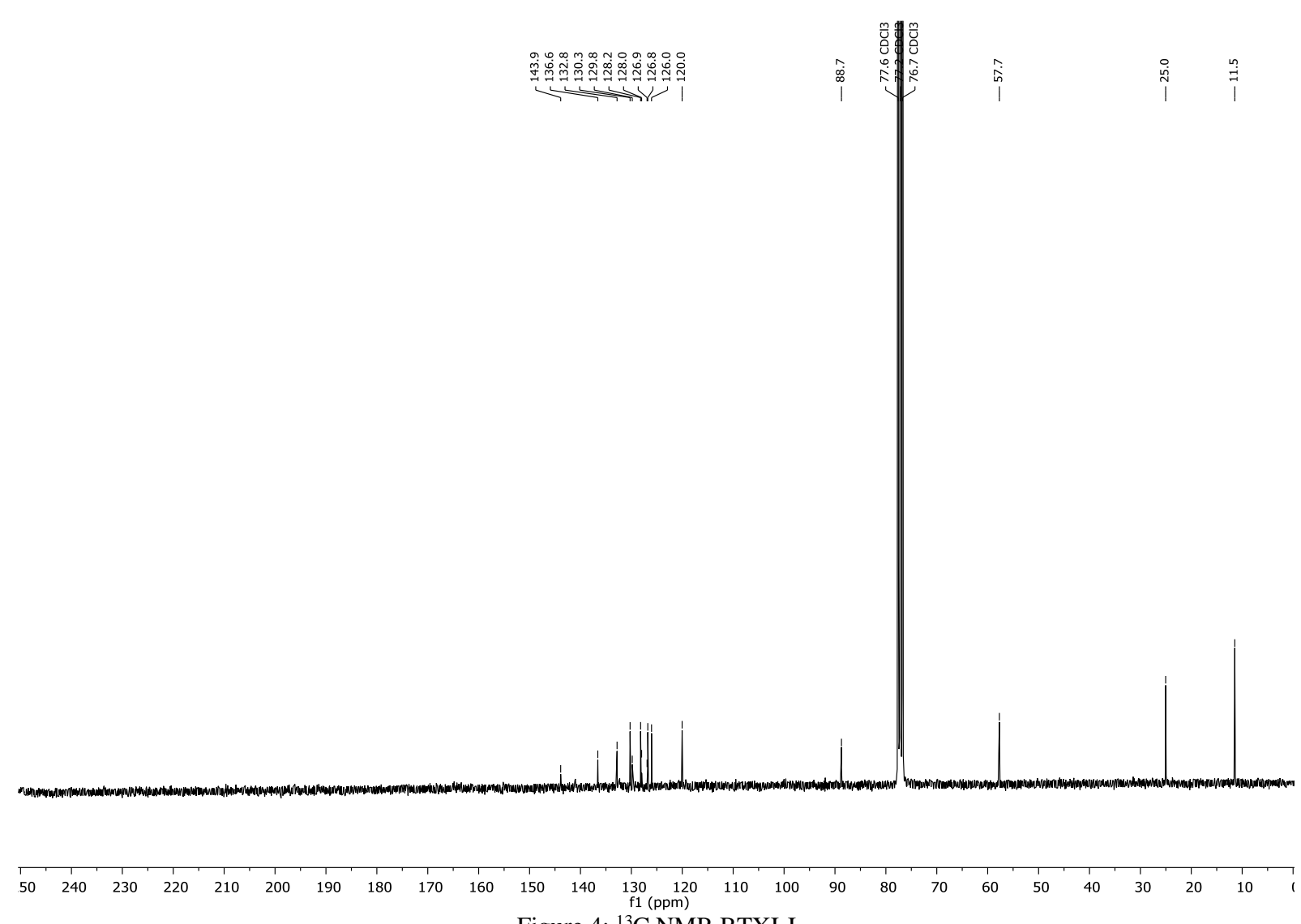

Figure 4: ${ }^{13} \mathrm{C}$ NMR BTXI-I 


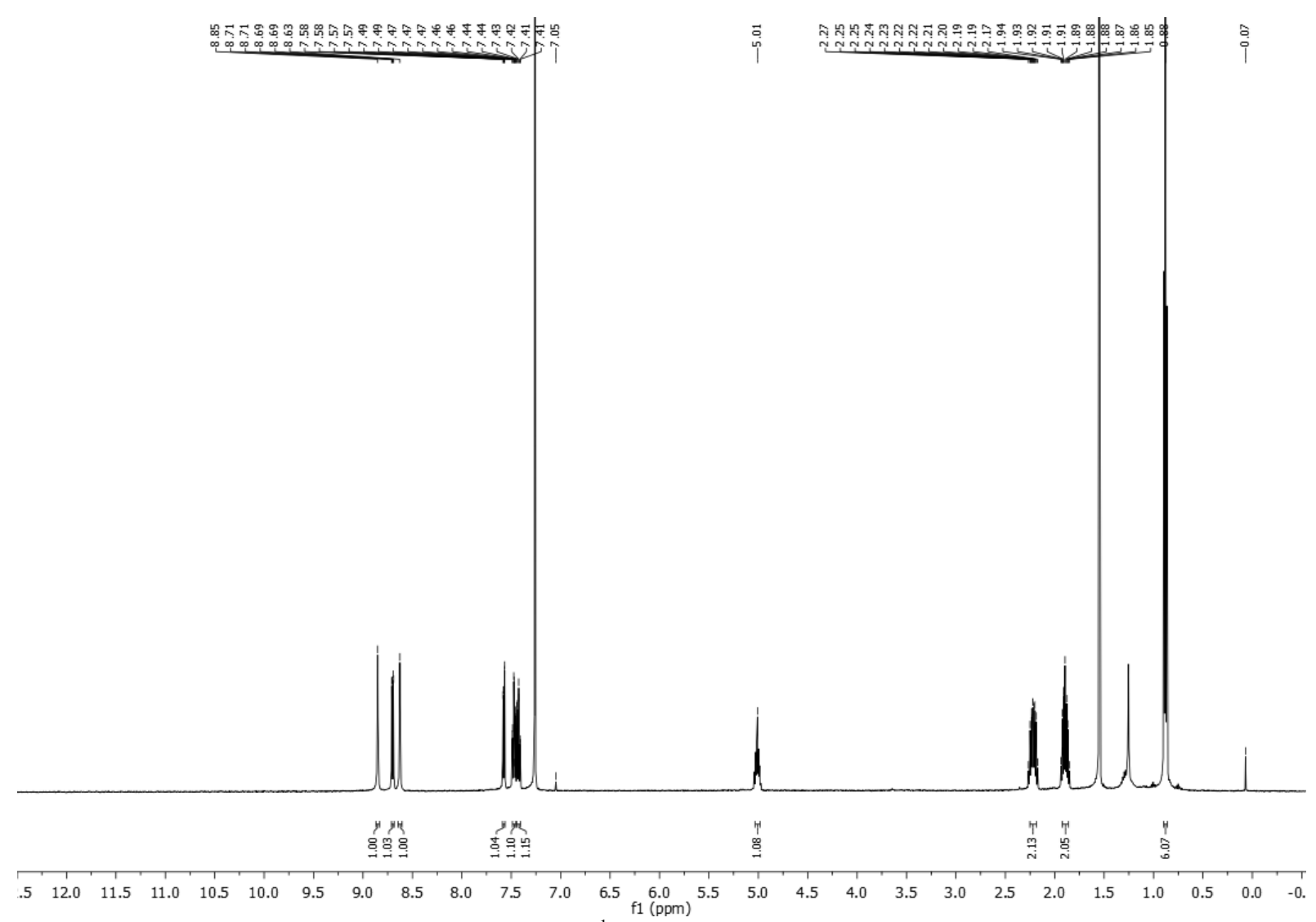

Figure 5: ${ }^{1} \mathrm{H}$ NMR Br-BTXI-Br

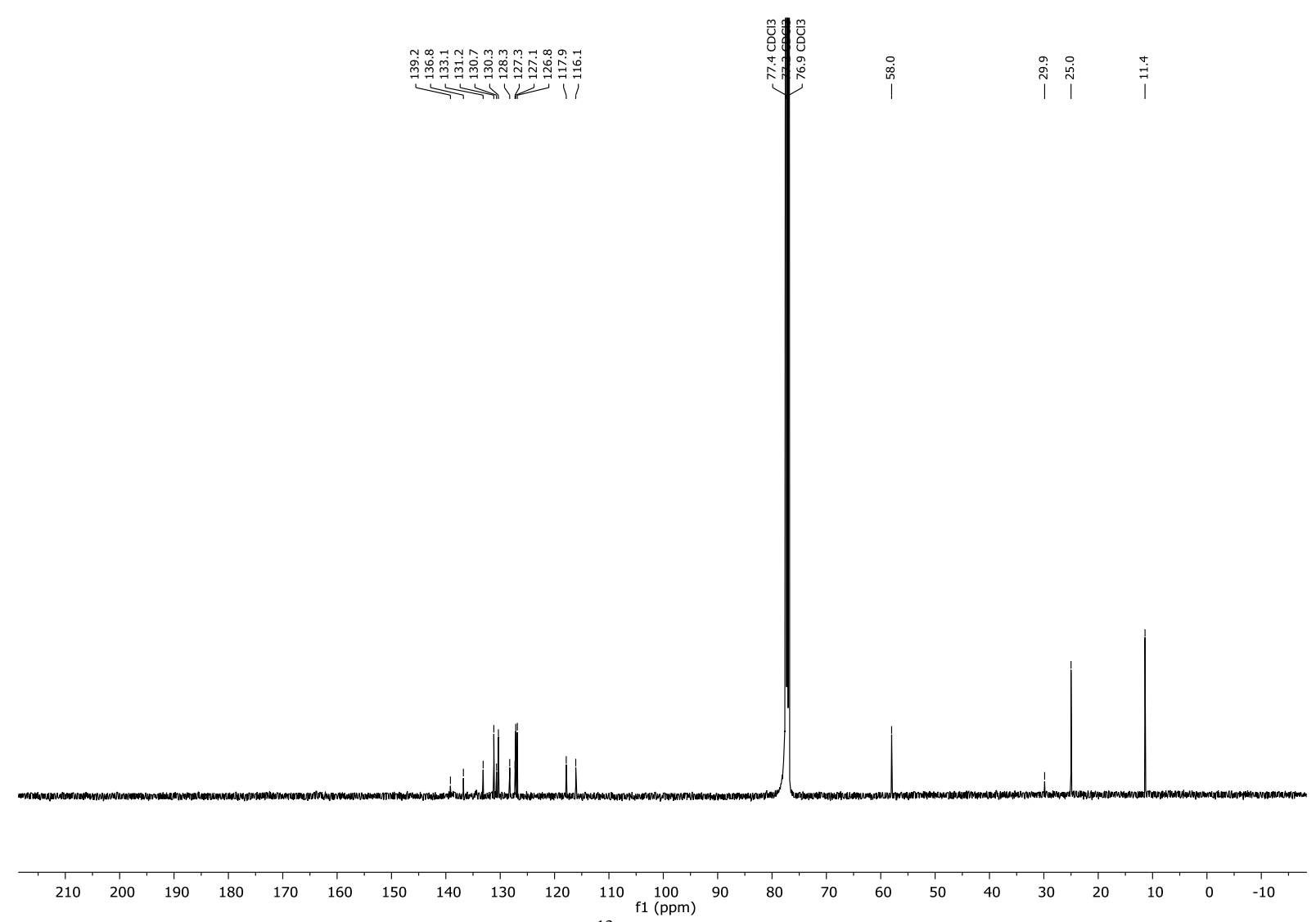

Figure 6: ${ }^{13} \mathrm{C}$ NMR Br-BTXI-Br 


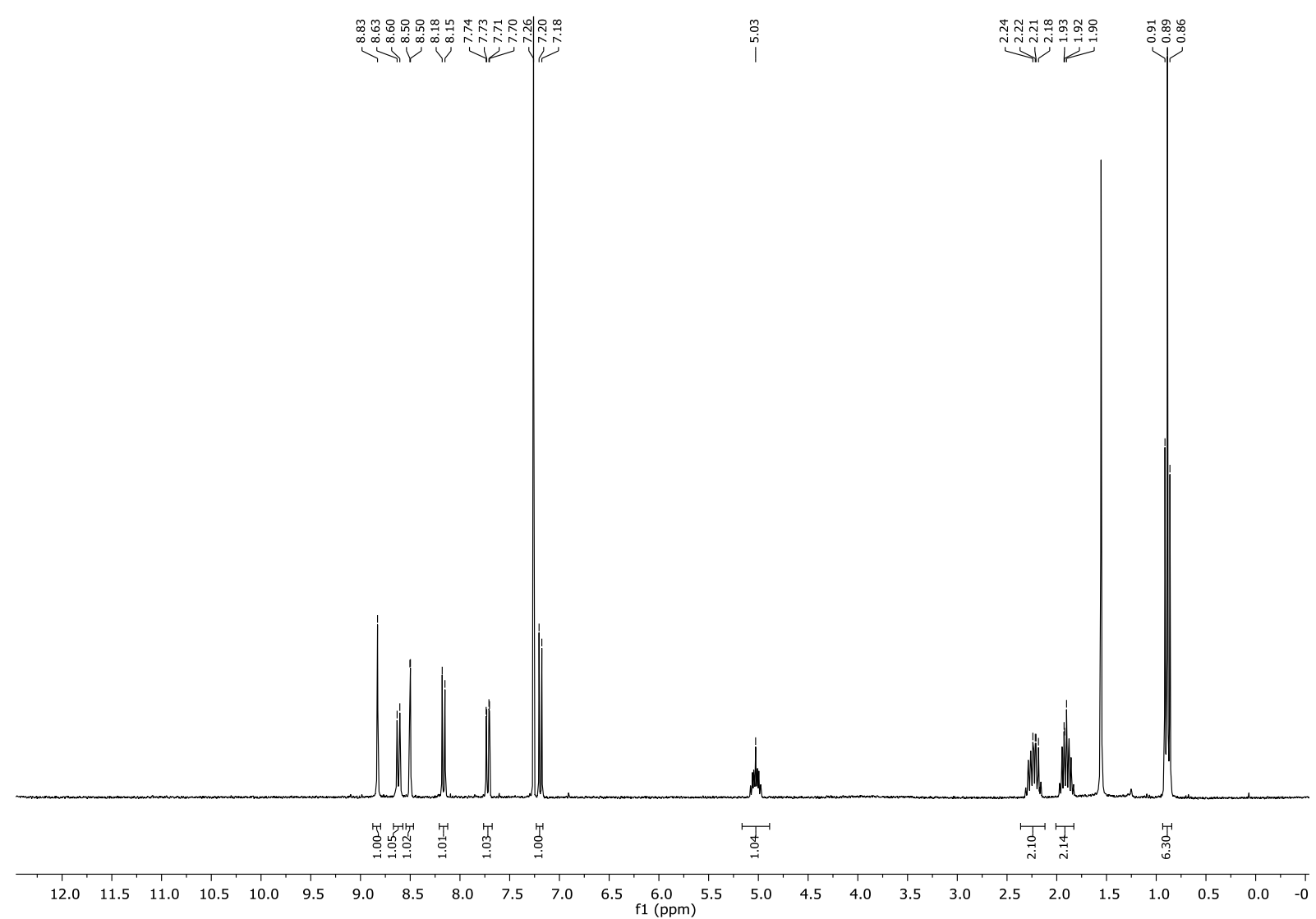

Figure 7: ${ }^{1} \mathrm{H}$ NMR I-BTXI-I

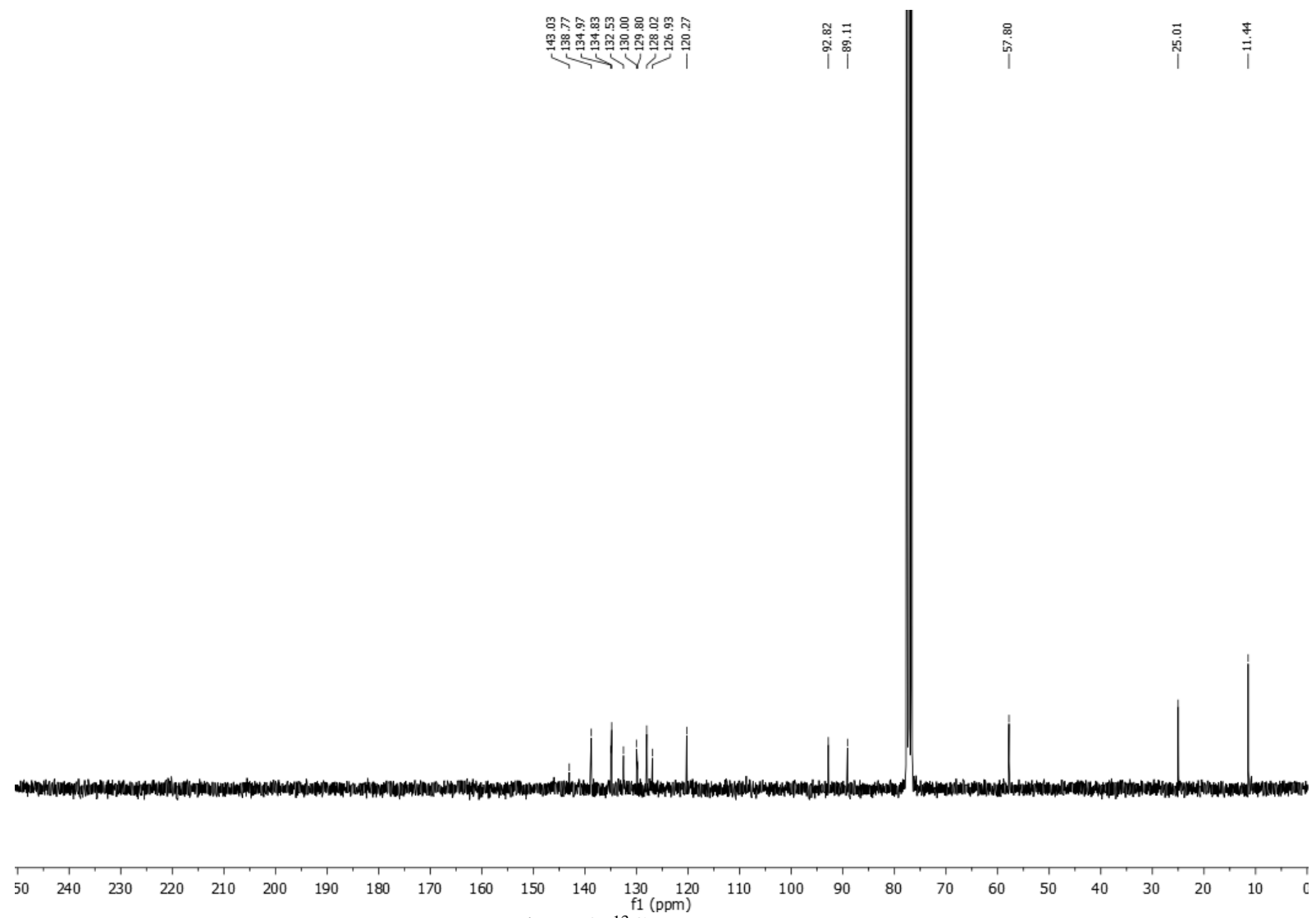

Figure 8: ${ }^{13} \mathrm{C}$ NMR I-BTXI-I 


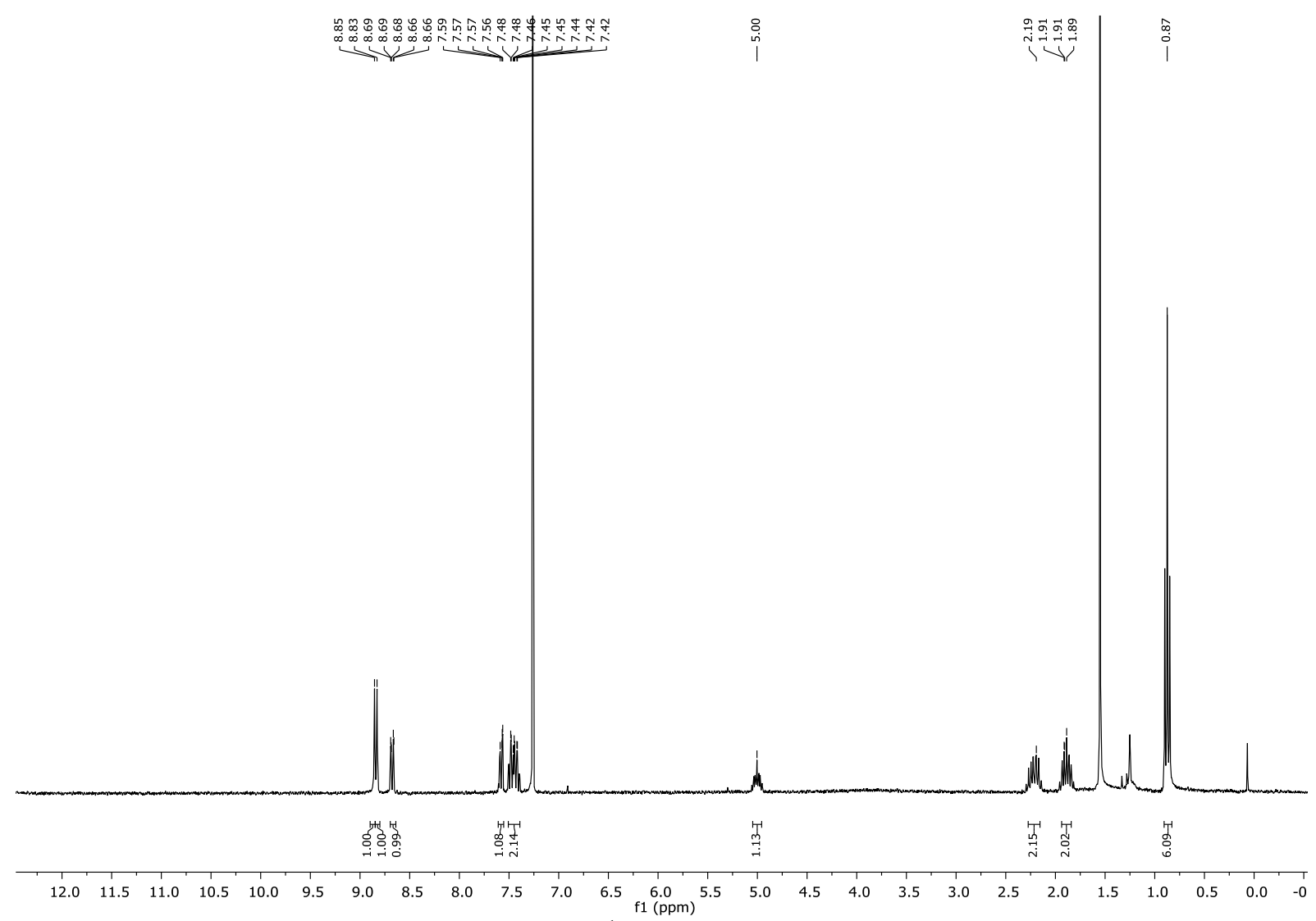

Figure 9: ${ }^{1} \mathrm{H}$ NMR Br-BTXI-I

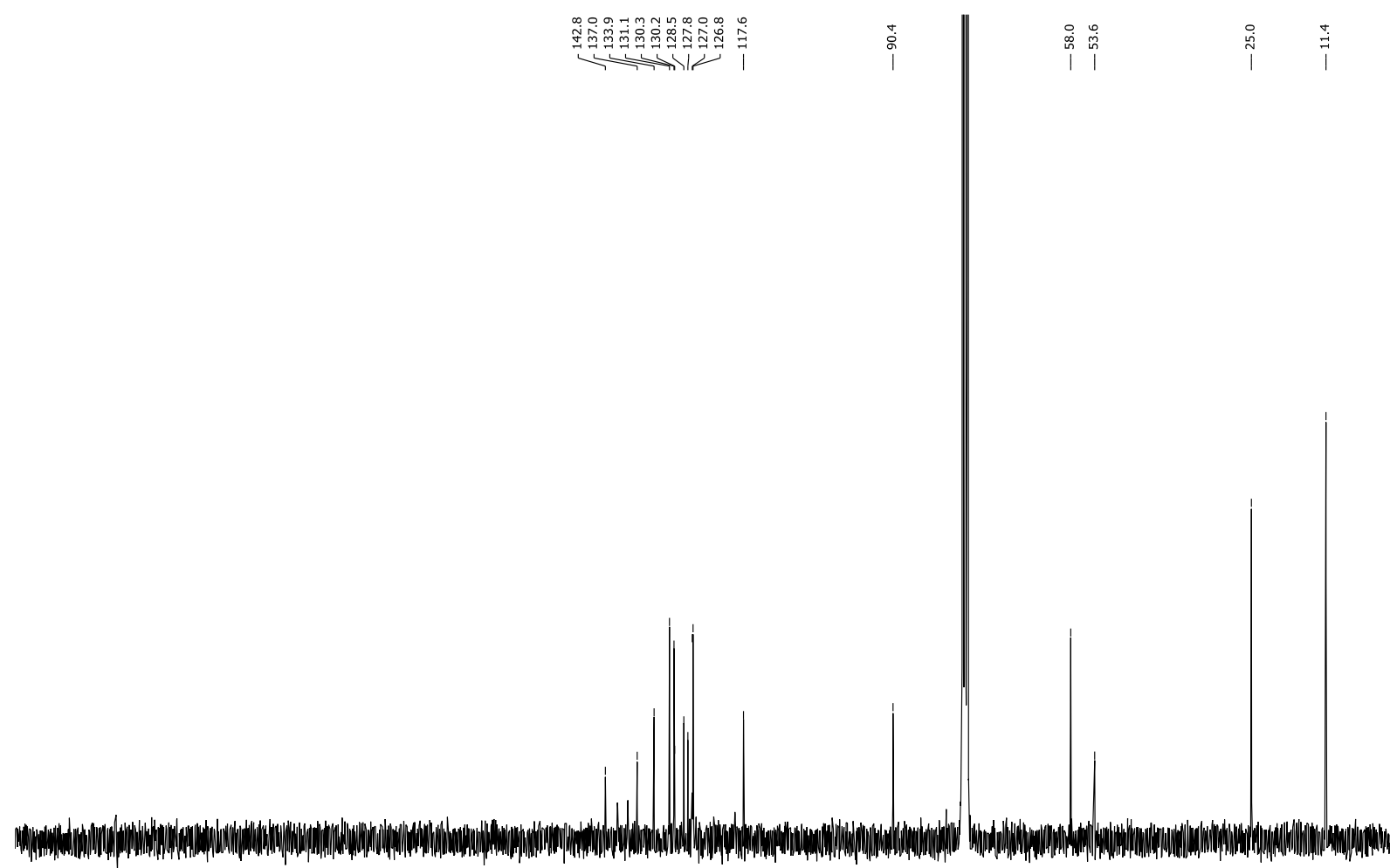

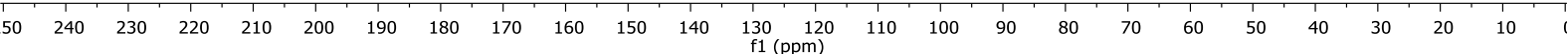
Figure 10: ${ }^{13} \mathrm{C}$ NMR Br-BTXI-I 


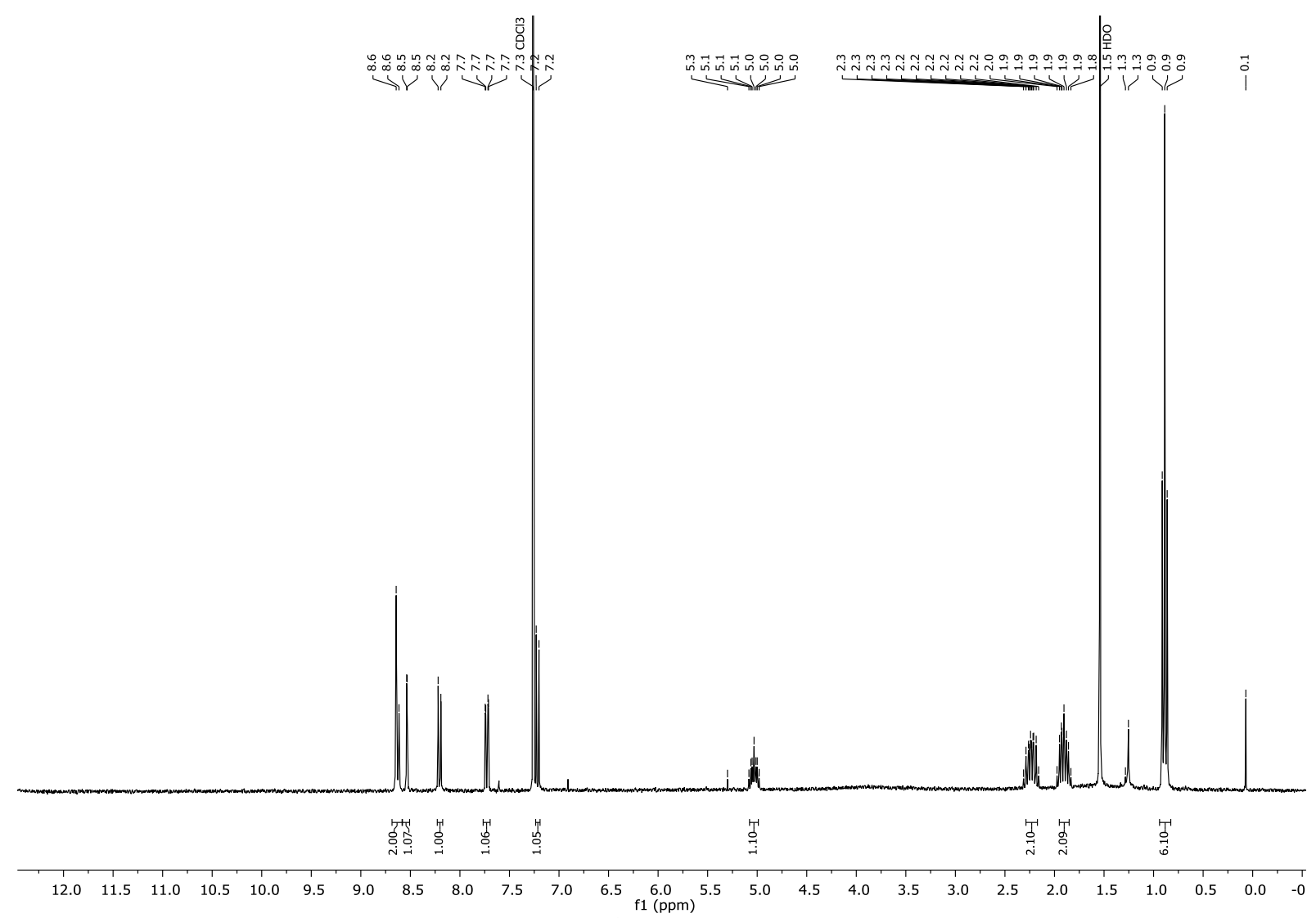

Figure 11: ${ }^{1} \mathrm{H}$ NMR I-BTXI-Br

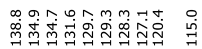

परोiा।

\a

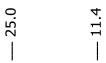

$\begin{array}{llllllllllllllllllllllllll}50 & 240 & 230 & 220 & 210 & 200 & 190 & 180 & 170 & 160 & 150 & 140 & \begin{array}{c}130 \\ \mathrm{f} 1(\mathrm{ppm})\end{array} & 110 & 100 & 90 & 80 & 70 & 60 & 50 & 40 & 30 & 20 & 10 & 1\end{array}$ Figure 12: ${ }^{13} \mathrm{C}$ NMR I-BTXI-Br 


\section{Mass Spectra}

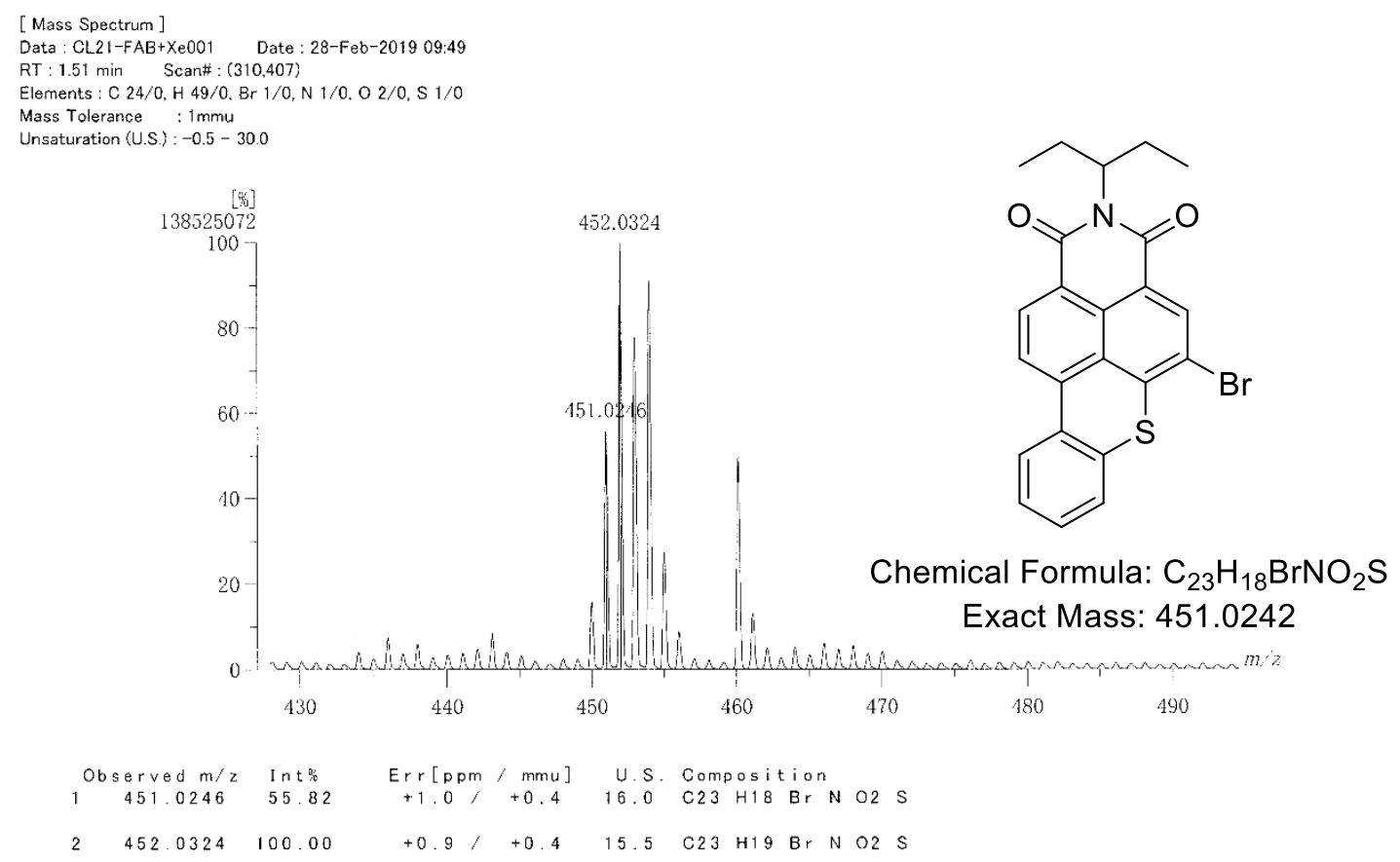

Figure 13: HRMS BTXI-Br

[ Mass Spectrum ]

Date : 29-Jan-2019 15:37

RT : 8.56 min Scan\# : $(2263,2376)$

Elements : C 24/0, H 49/0, N 1/0, O 2/0, S 1/0, I1/0

Mass Tolerance : $1000 \mathrm{ppm}, 1 \mathrm{mmu}$ if $\mathrm{m} / \mathrm{z}>1$

Unsaturation (U.S.) : $-0.5-30.0$

5787825
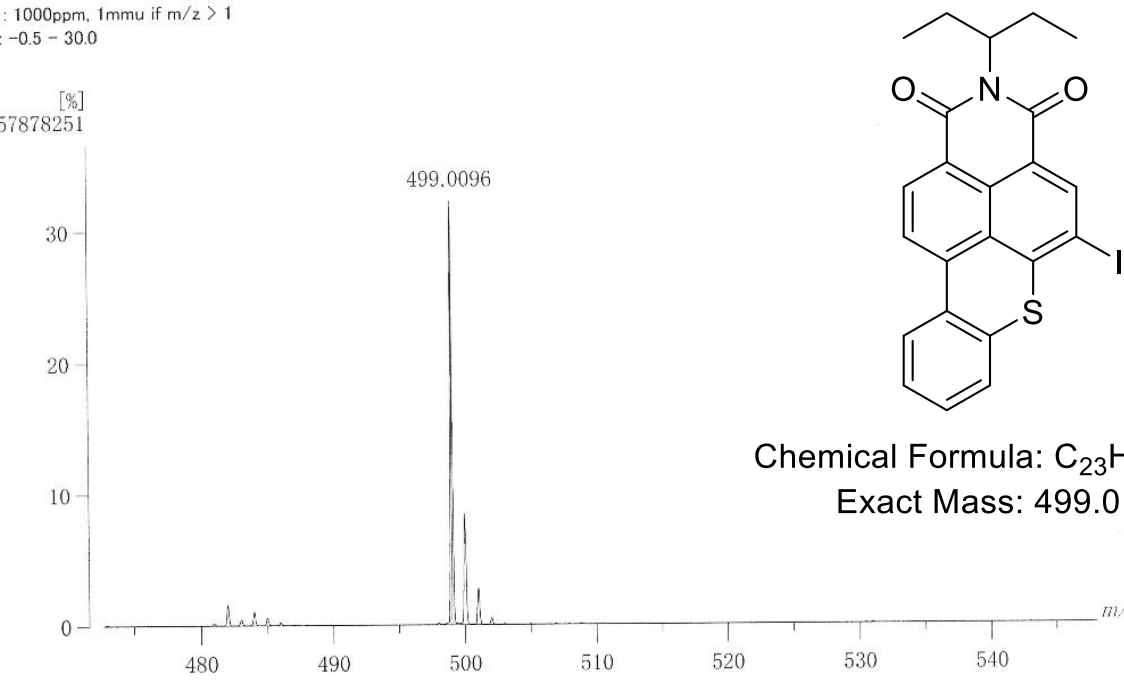

Chemical Formula: $\mathrm{C}_{23} \mathrm{H}_{18} \mathrm{INO}_{2} \mathrm{~S}$

Exact Mass: 499.0103

$\begin{array}{cccccc}\text { Observed m/z } & \text { Int\% } \\ 1 & 499.0096 & 32.32 & \text { Err }[p p m / \text { mmu }] & \text { U.S. Composition } \\ 1 & -1.4 / & -0.7 & 16.0 & \text { C23 H18NO2 S I }\end{array}$

Figure 14: HRMS BTXI-I 
[ Mass Spectrum ]

Data : Spiro05-E1003 Date : 24-Jan-2019 10:52

RT : $3.12 \mathrm{~min}$ Scan\# : (1016,1093)

Elements : C 24/0, H 49/0, Br 2/0, N 1/0, O 2/0, S $1 / 0$

Mass Tolerance : $1000 \mathrm{ppm}, 1 \mathrm{mmu}$ if $\mathrm{m} / \mathrm{z}>1$

Unsaturation (U.S.) : $-0.5-50.0$

41650620
100

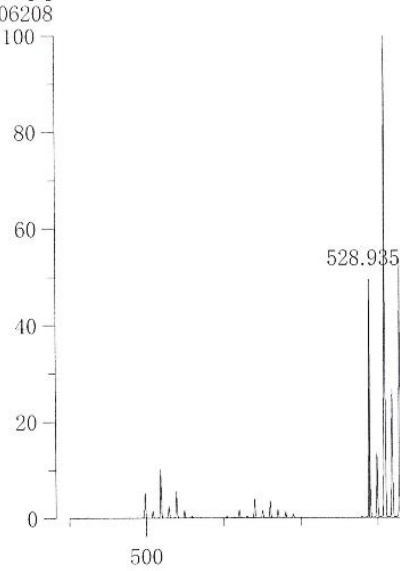<smiles></smiles>

Chemical Formula: $\mathrm{C}_{23} \mathrm{H}_{17} \mathrm{Br}_{2} \mathrm{NO}_{2} \mathrm{~S}$ Exact Mass: 528.9347

Observed $\mathrm{m} / \mathrm{z}$ Int $\mathrm{h}$ Err[ppm / mmu] U.S. Composition

$1528.9352+49.41+1.0,+0.5 \quad 16.0$ C23 H17 Br2 NO2

Figure 15: HRMS Br-BTXI-Br

[ Mass Spectrum ]

Data : spiro67-E1001 Date : 09-Apr-2019 10:56

RT : $14.65 \mathrm{~min} \quad$ Scan\# : (4531,4817)

Elements : C 24/0, H 49/0, Br 1/0, N 1/0, O 2/0, S 1/0, I 1/0

Mass Tolerance : $2 \mathrm{mmu}$

Unsaturation (U.S.) : $-0.5-30.0$

30700794

\section{$[\%]$
7940}

40
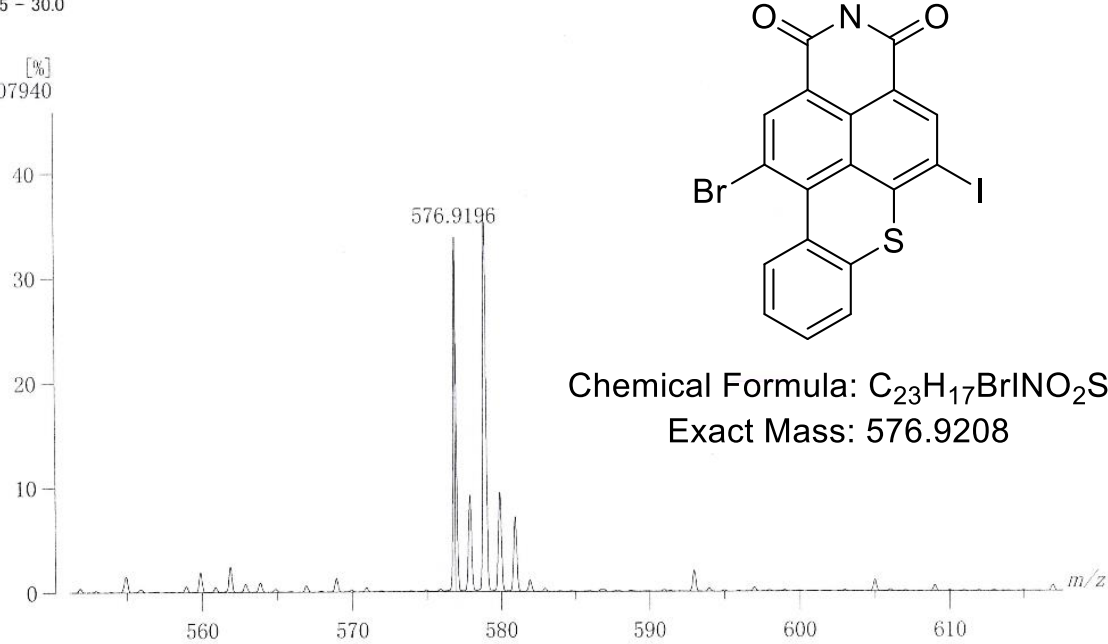

Observed $\mathrm{m} / \mathrm{z}$ Int\% Err[ppm/ mmu] U.S. Composition

$1 \quad 576.9196 \quad 33.88 \quad-2.1 /-1.2 \quad 16.0 \quad$ C23 H17 Br N O2 S I

Figure 16: HRMS Br-BTXI-I 
[ Mass Spectrum ]

Data: spiro69-FABnegXe001 Date : 11-Apr-2019 15:27

RT $: 7.87 \mathrm{~min} \quad$ Scan\# $:(987,1104)$

Elements : C 24/0, H 49/0, Br 1/O, N-1/0, O 2/0, S 1/0, I 1/0

Mass Tolerance : $1000 \mathrm{ppm}, 1 \mathrm{mmu}$ if $\mathrm{m} / \mathrm{z}>1$

Unsaturation (U.S.) : $-0.5-30.0$

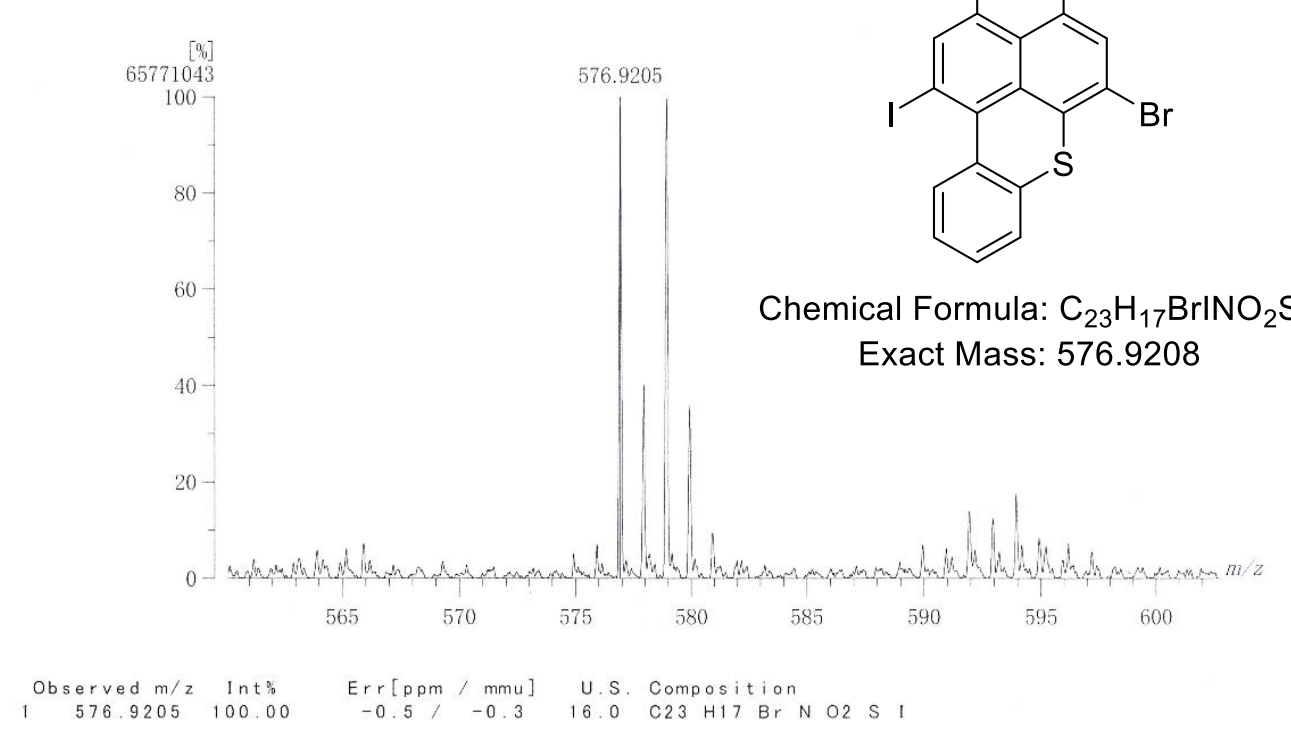

Figure 17: HRMS I-BTXI-Br

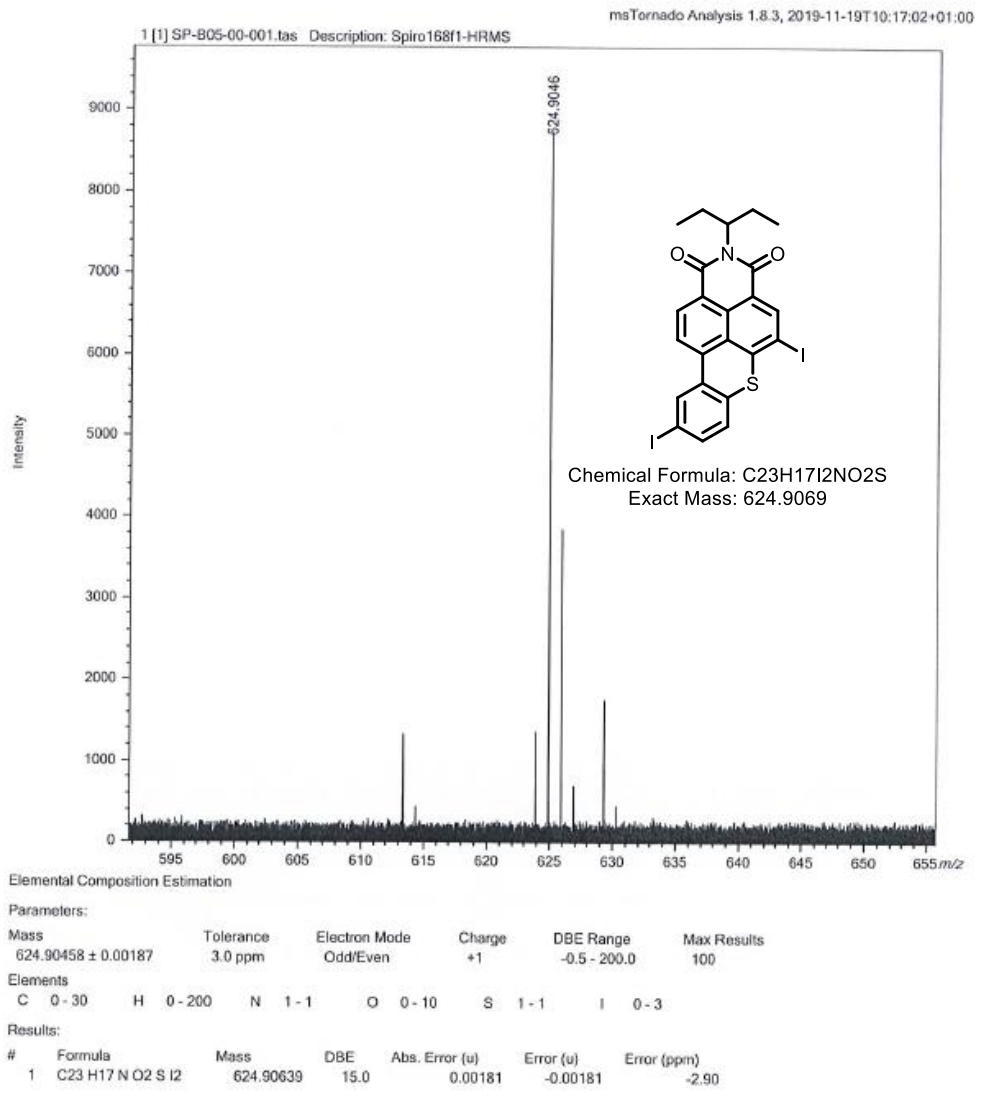

Figure 18: HRMS I-BTXI-I 


\section{Crystallographic data}

The I-BTXI-I structure showed disordered electron density which could not be reliably modeled and the program PLATON/SQUEEZE (A.L. Spek V270519 (1980-2019)) was used to remove the corresponding scattering contribution from the intensity data. This electron density can be attributed to toluene molecules and the assumed solvent composition was used in the calculation of the empirical formula, formula weight, density, linear absorption coefficient, and $\mathrm{F}(000)$.

\begin{tabular}{|c|c|c|c|c|c|}
\hline Crystal & $\begin{array}{c}\text { 2(Br-BTXI-Br), } \\
\text { PhMe }\end{array}$ & BTXI-I & 3(I-BTXI-I), PhMe & I-BTXI-Br & Br-BTXI-I \\
\hline Formula & $\mathrm{C}_{53} \mathrm{H}_{42} \mathrm{Br}_{4} \mathrm{~N}_{2} \mathrm{O}_{4} \mathrm{~S}_{2}$ & $\mathrm{C}_{23} \mathrm{H}_{18} \mathrm{INO}_{2} \mathrm{~S}$ & $\mathrm{C}_{76} \mathrm{H}_{59} \mathrm{I}_{6} \mathrm{~N}_{3} \mathrm{O}_{6} \mathrm{~S}_{3}$ & $\mathrm{C}_{23} \mathrm{H}_{17} \mathrm{BrINO}_{2} \mathrm{~S}$ & $\mathrm{C}_{23} \mathrm{H}_{17} \mathrm{BrINO}_{2} \mathrm{~S}$ \\
\hline Molecular Weight & 1154.64 & 499.34 & 1967.84 & 578.24 & 578.24 \\
\hline Temperature (K) & 200 & 293 & 150 & 295 & 295 \\
\hline Crystal system & Monoclinic & Monoclinic & Trigonal & Monoclinic & Orthorhombic \\
\hline Space group & $P 21 / c$ & $P 21 / n$ & $P-3$ & $P 21 / c$ & $P b c n$ \\
\hline a $(\AA)$ & $20.8497(3)$ & $14.1742(4)$ & $23.5066(2)$ & $7.4020(2)$ & $22.5232(7)$ \\
\hline $\mathrm{b}(\AA)$ & $7.4879(1)$ & $12.1233(3)$ & $23.5066(2)$ & $17.7593(3)$ & $7.4885(3)$ \\
\hline$c(\AA)$ & $29.7763(5)$ & $22.8334(5)$ & $7.3117(1)$ & $31.1827(5)$ & $24.3955(9)$ \\
\hline$\alpha\left(^{\circ}\right)$ & 90 & 90 & 90 & 90 & 90 \\
\hline$\beta\left(^{\circ}\right)$ & $94.603(1)$ & $90.112(2)$ & 90 & $91.047(2)$ & 90 \\
\hline$\gamma\left({ }^{\circ}\right)$ & 90 & 90 & 120 & 90 & 90 \\
\hline$V\left(\AA^{3}\right)$ & 4633.7(1) & $3923.6(2)$ & $3498.88(8)$ & 4098.4(1) & $4114.7(3)$ \\
\hline $\mathrm{Z}$ & 4 & 8 & 2 & 8 & 8 \\
\hline Crystal color & Orange & Orange & Orange & Orange & Orange \\
\hline Crystal size $\left(\mathrm{mm}^{3}\right)$ & $0.37 \times 0.076 \times 0.04$ & $0.31 \times 0.039 \times 0.028$ & $0.148 \times 0.04 \times 0.034$ & $0.253 \times 0.12 \times 0.042$ & $0.278 \times 0.058 \times 0.02$ \\
\hline$D_{c}\left(\mathrm{~g} \mathrm{~cm}^{-3}\right)$ & 1.655 & 1.691 & 1.868 & 1.874 & 1.867 \\
\hline$F(000)$ & 2312 & 1984 & 1900 & 2256 & 2256 \\
\hline$\mu\left(\mathrm{mm}^{-1}\right)$ & 5.481 & 13.973 & 22.197 & 15.680 & 15.618 \\
\hline Trans (min/max) & $0.50637 / 1.000$ & $0.54479 / 1.000$ & $0.49257 / 1.000$ & $0.24965 / 1.000$ & $0.58802 / 1.000$ \\
\hline$\theta(\min / \max )\left(^{\circ}\right)$ & $2.978 / 72.067$ & $3.667 / 72.186$ & $3.761 / 74.066$ & $2.835 / 73.549$ & $3.624 / 73.982$ \\
\hline Data collected & 16509 & 15962 & 16286 & 18110 & 10332 \\
\hline Data unique & 8756 & 7511 & 4650 & 8065 & 4073 \\
\hline Data observed & 7551 & 6434 & 4370 & 7295 & 3575 \\
\hline$R$ (int) & 0.0293 & 0.0328 & 0.0233 & 0.0313 & 0.0310 \\
\hline Parameters & 599 & 509 & 283 & 527 & 264 \\
\hline$R_{1} /[I>2 \sigma(I)]$ & 0.0389 & 0.0365 & 0.0193 & 0.0383 & 0.0295 \\
\hline$w R_{2}[\mathrm{I}>2 \sigma(\mathrm{I})]$ & 0.0982 & 0.0920 & 0.0523 & 0.1101 & 0.0725 \\
\hline$R_{1}$ [all data] & 0.0461 & 0.0441 & 0.0211 & 0.0416 & 0.0344 \\
\hline$w R_{2}$ [all data] & 0.1039 & 0.0987 & 0.0536 & 0.1143 & 0.0766 \\
\hline GOF & 1.031 & 1.014 & 0.899 & 1.025 & 1.029 \\
\hline $\begin{array}{l}\text { Largest diff. peak } \\
\text { and hole }\left(e . A^{-3}\right)\end{array}$ & $1.305 /-0.415$ & $0.781 /-0.750$ & $0.659 /-0.856$ & $1.197 /-0.722$ & $0.554 /-0.546$ \\
\hline CCDC number & 1970428 & 1970429 & 1970430 & 1970431 & 1970434 \\
\hline
\end{tabular}


Regioselective mono and homohetero dihalogenation of th... (2.21 MiB) view on ChemRxiv • download file 